\title{
PREPARATION AND CHARACTERIZATION OF PVA COMPOSITES WITH CELLULOSE NANOFIBERS OBTAINED BY ULTRASONICATION
}

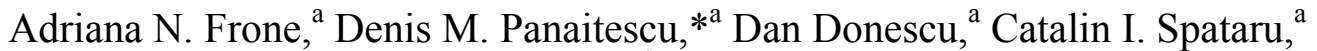 \\ Constantin Radovici, ${ }^{\mathrm{a}}$ Roxana Trusca, ${ }^{\mathrm{b}}$ and Raluca Somoghi ${ }^{\mathrm{a}}$
}

\begin{abstract}
Cellulose nanofibers were obtained from microcrystalline cellulose (MCC) by the action of hydrodynamic forces associated with ultrasound. Nanofibers isolated from MCC by applying different ultrasonication conditions were characterized to elucidate their morpho-structural features by field emission scanning electron microscopy, atomic force microscopy, X-ray diffraction, and dynamic light scattering. Several differences were observed regarding the size of the nanofibers obtained in different ultrasonic conditions, but no significant changes in the crystalline structure of cellulose nanofibers were detected. The obtained cellulose fibers were used at low levels ( 1 to $5 \mathrm{wt} . \%$ ) as reinforcements in a poly(vinyl alcohol) (PVA) matrix. The mechanical and thermal properties of the PVA/cellulose fibers nanocomposites films were determined. The tensile strength and modulus of the PVA film were significantly improved by the addition of cellulose nanofibers. Slightly higher onset degradation temperatures were obtained for PVA composites in comparison to neat PVA, showing an increase of the thermal stability caused by the addition of cellulose fibers.
\end{abstract}

Keywords: Cellulose nanofibers; Ultrasonication; Poly(vinyl alcohol); Nanocomposites; Mechanical properties

Contact informations: a: National Institute for Research and Development in Chemistry and Petrochemistry, Polymer Department, 202 Spl. Independentei, 060021, Bucharest, Romania; b: METAV Research and Development SA, 31 C.A Rosetti Street, Bucharest, Romania; *Corresponding author: panaitescu@icf.ro

\section{INTRODUCTION}

In the last decade, increasing environmental awareness has led to growing interest in the development of materials with eco-friendly attributes. Owing to their good mechanical properties, polymer composites with cellulose fibers (with micro or nano size) are able to substitute for glass-fiber-containing composites in some important applications such as automotive or construction and have found potential applications in biomedical and cosmetic industries, the electrical and electronic field, and the paper, and packaging industry (Hoenich 2006; Lee 2006; Petersson and Oksman 2006; Dong and Roman 2007; Panaitescu et al. 2007a,b,c; Wang and Sain 2007; Hubbe et al. 2008; Ioelovich 2008; Kamel 2009).

The production of nano-scale cellulose fibers and their application in composite materials has gained increasing attention in recent times. Two different types of 
nanoreinforcements can be isolated from a cellulosic source: nanofibers and nanocrystals/ nanowhiskers (Petersson et al. 2009; Elazzouzi-Hafraoui et al. 2008). Nanofibers are fibrilar units resulting from the linear combination of cellulose macromolecules that contain both amorphous and crystalline regions of cellulose and have the ability to create entangled networks. Cellulose nanocrystals can have a perfect crystalline structure and high modulus, close to the theoretical modulus of cellulose (Eichhorn et al. 2010).

Considerable research has been done regarding the extraction of cellulose nanofibers from different sources and on preparing polymer composites with these fibers (Nakagaito et al. 2004; Yano et al. 2005; Nakagaito and Yano 2008; Nogi et al. 2006; Chakraborty et al. 2005). The mechanical and chemical treatments have been the most applied methods to obtain cellulose nanofibers. Nakagaito and Yano (2004) obtained cellulose nanofibers from kraft pulp after repeated passes (16 to 30) through a refiner and prepared a composite with improved mechanical properties based on a phenolic resin reinforced with these fibers. Chakraborty et al. (2005) applied combined mechanical techniques to obtain cellulose microfibers from bleached kraft pulp, employing severe shearing in a refiner, followed by high-impact crushing under liquid nitrogen. Cellulose whiskers with a length between 200 and $400 \mathrm{~nm}$ were isolated from microcrystalline cellulose (MCC) by acid hydrolysis using sulphuric acid with a concentration of $63.5 \%$ (Bondenson et al. 2006). By a combination of chemical and mechanical treatments, Jonoobi et al. (2009) isolated nanofibers from unbleached and bleached kenaf pulp. The obtained nanofibers showed higher crystallinity and thermal stability as compared to the raw kenaf. Lee et al. (2009) obtained nanocellulose by acid hydrolysis of MCC using different hydrobromic acid concentrations. PVA composites prepared with these nanocelluloses showed significantly improved tensile and thermal properties. Panaitescu et al. (2007b) prepared polypropylene composites with cellulose fibers obtained through mechano-chemical treatment of bleached pulp and $\alpha$-cellulose. These composites exhibited higher tensile strength and elastic modulus than neat polypropylene.

All of the above mentioned methods used for cellulose nanofibers isolation have some drawbacks: they involve high consumption of energy for such processes as mechanical treatments by refining, homogenisation, or grinding (Nakagaito and Yano 2004), or the fabrication processes can cause deterioration of the environment, as in the case of chemical treatments (De Souza Lima et al. 2004). Current research has been focused on finding new environmentally friendly methods to isolate cellulose fibers, characterized by high efficiency and low costs. To address this goal, ultrasonication has been employed alone or in combination with acid hydrolysis to obtain cellulose fibers in a few laboratory tests (Filson and Dawson-Andoh 2009; Zhang et al. 2007; Cheng and Wang 2008; Oksman et al. 2006; Li and Renneckar 2009). High intensity ultrasonication can be a powerful and clean method of defibrillation of cellulose sources. Ultrasonic waves produce strong mechanical stresses due to cavitation, causing disaggregation of cellulose fibers into smaller entities (Zhang et al. 2007; Wang and Cheng 2009).

Several attempts to prepare polymer composites with cellulose nanofibers using polymeric matrices with hydrophilic character such as starch, polyethylene oxide, poly (vinyl alcohol), or polyethylene glycol have been reported (Kvien et al. 2007; Alemdar and Sain 2008; Yano and Nakahara 2004; Famá et al. 2009; Azizi et al. 2005; Kvien and Oksman 2007; Roohani et al. 2008; Yan and Gao 2008; Yuan and Ding 2006). 
Nanocomposite films with improved mechanical properties were obtained by dispersing cellulose nanofibers $(5 \%)$ into a starch matrix, emphasizing the reinforcing effect of cellulose nanofibers (Kvien et al. 2007).

Poly(vinyl alcohol) (PVA) is a water-soluble and biodegradable polymer with excellent chemical resistance; as such it is an interesting material for high-tech applications (Zhang et al. 2009). PVA has no toxic action on the human body and is used to manufacture medicines cachets, yarn for surgery, and controlled drug delivery systems (Tang et al. 2009). Development of eco-friendly packaging materials is a challenging area, and many studies have been focused on the improvement of PVA's mechanical and barrier properties by combination with other polymers or fillers in order to use it in the packaging industry (Sedlarik et al. 2006). For many other applications, the mechanical properties of PVA should be substantially improved without damaging its other valuable properties such as transparency and flexibility.

The main goal of this work was to employ different ultrasonic conditions in order to isolate nanofibers from microcrystalline cellulose and to evaluate the reinforcing ability of small amounts of these fibers in a PVA matrix. A low concentration of cellulose fibers was preferred in order to preserve the transparency and flexibility of PVA films. PVA was chosen as a matrix because of the above specified advantages and the expected interaction of its hydroxyl groups with the hydrophilic surfaces of the cellulose nanofibers, leading to strong hydrogen bonding. Although several attempts to separate the cellulose nanofibers from various sources of cellulose using only high power ultrasonication have appeared in the literature (Wang et al. 2009; Wu et al. 2009), especially in recent years, it has not been tried yet, as our knowledge, to use fibers obtained in this way to reinforce PVA, and the influence of ultrasonic conditions on the properties of obtained fibers and composites have not yet been investigated.

Nanofibers were characterized by field emission scanning electron microscopy (FE-SEM), atomic force microscopy (AFM), X-ray diffraction (XRD), and dynamic light scattering (DLS). The mechanical and thermal properties of PVA nanocomposites prepared with these nanofibers were also determined.

\section{EXPERIMENTAL}

\section{Materials}

Microcrystalline cellulose (MCC) with a mean particle size of $20 \mu \mathrm{m}$ and an aspect ratio of 2 to 4, purchased from Sigma-Aldrich, was used as raw material for the preparation of nanofibers. Poly(vinyl alcohol), PVA 120-99, 1200 polymerization degree and 99\% hydrolysis degree, was purchased from Chemical Enterprise Râsnov (Romania) and was used for nanocomposites preparation.

\section{Nanofibers Isolation}

To obtain cellulose nanofibers from microcrystalline cellulose, the MCC was dispersed under continuous stirring in distilled water $(1 / 500)$ and sonicated using an ultrasonicator type Vibra Cell VC505 (500 W, $20 \mathrm{KHz})$, equipped with a sonication probe of $19 \mathrm{~mm}$. The concentration of MCC in distilled water was $0.2 \%$, the size of a 
sample being ca. $500 \mathrm{~mL}$. In order to prevent the uncontrolled increase of temperature, the beaker with the cellulose suspension was put in a water bath with controlled temperature. Different ultrasonication powers and times were used (Table 1). Sample temperature was measured at the end of the ultrasonic treatment and it did not exceed $50^{\circ} \mathrm{C}$. The appearance of non-settling turbidity in the supernatant was a definite indication of the presence of cellulose nanofibers (Chen et al. 2010; Petersson et al. 2007; Bondenson et al. 2006)

Table 1. Parameters of Ultrasonication Process and Cellulose Samples Symbols

\begin{tabular}{||c|c|c|c||}
\hline \hline Sample7 & \multirow{2}{*}{$\begin{array}{c}\text { Power } \\
(\mathrm{W})\end{array}$} & $\begin{array}{c}\text { Ultrasonication time } \\
(\mathrm{min})\end{array}$ & $\begin{array}{c}\text { Energy } \\
(\mathrm{KJ})\end{array}$ \\
\cline { 1 - 2 } U1 & \multirow{2}{*}{200} & 10 & 21.9 \\
\cline { 1 - 2 } U2 & \multirow{2}{*}{400} & 20 & 52.1 \\
\cline { 1 - 2 } \cline { 3 - 4 } U3 & 10 & 78.9 \\
\hline U4 & & 20 & 164.8 \\
\hline
\end{tabular}

Samples of cellulose nanofibers (supernantant) were obtained from the water suspensions by decanting the supernatant into other vessels, two hours after the sonication process ended. The cellulose samples U1, U2, U3, and U4, obtained under the conditions specified in Table 1, were characterized by means of dynamic light scattering, by microscopic techniques, and by X-ray diffraction.

\section{Nanocomposite Films Preparation}

In order to obtain PVA/cellulose fiber composite films with different filler concentrations, the required amount of PVA corresponding to a final concentration of $10 \%$ in the aqueous medium and the calculated amount of U1...U4 cellulose fibers suspensions to achieve 1,3 , and $5 \mathrm{wt} \%$ filler concentration in the final composite were mixed using a high speed stirrer $\left(500 \mathrm{~min}^{-1}\right)$. The stirring was performed at $80^{\circ} \mathrm{C}$ for 3 hours, and the resulting mixture was degassed for approximately 15 minutes in an Elmasonic S40 H ultrasonic bath. The films were cast on a PET plate and were kept at room temperature for two days until they were completely dried and then removed from the PET plates and placed in a desiccator for three days before mechanical characterization. Neat PVA films were obtained under similar conditions.

\section{Experimental Methods}

\section{Cellulose fibers characterization}

FE-SEM micrographs were obtained with a Quanta Inspect F Scanning Electron Microscope with a field emission gun having a resolution of $1.2 \mathrm{~nm}$ at an accelerating voltage of $30 \mathrm{kV}$. A droplet from the undiluted suspensions was put on a glass grid and dried under vacuum before FE-SEM analysis. All the samples were sputter-coated with gold before examination.

AFM images were captured in tapping mode by a MultiMode 8 atomic force microscope equipped with a Nanoscope V converter (Veeco, Santa Barbara, CA). Real time scanning was performed in air at room temperature with scan rates of $1 \mathrm{~Hz}$ and scan angle $0^{\circ}$. A silicon tip (nominal radius $8 \mathrm{~nm}$ from Veeco) with a cantilever length of 225 
$\mu \mathrm{m}$ and a resonant frequency of about $75 \mathrm{kHz}$ was used. The height and phase signal were recorded simultaneously and the images (256x256) were recorded and analyzed using the AFM software NanoScope version 1.20. Droplets of undiluted aqueous suspensions of $\mathrm{U} 1$ and $\mathrm{U} 4$ nanofibers were placed on a glass substrate and allowed to dry under vacuum before AFM analysis.

The crystallinity of cellulose fibers was determined by XRD with a DRON-UM diffractometer (horizontal goniometer Bragg-Brentano) using $\mathrm{Co} \mathrm{K} \alpha$ radiation (wavelength $\lambda=1.79021 \AA$ ), scanning from the $2 \theta$ value of $4^{\circ}$ to $36^{\circ}$ at a scanning rate of $0.05^{\circ} / 5 \mathrm{sec}$. Samples were analyzed in reflection mode after drying 4 hours at $40^{\circ} \mathrm{C}$.

The size distribution of cellulose aggregates was estimated by dynamic light scattering (DLS) using a Zetasizer Nano ZS instrument (Malvern, UK). The DLS measurements were performed with an angle of $170^{\circ}$ by using a $\mathrm{He}-\mathrm{Ne}$ laser $(4 \mathrm{~mW})$ operated at $633 \mathrm{~nm}$, on the samples themselves (supernatant). DLS analysis has been developed for measuring the dimensions of spherical particles, so that the measurement of rod-shaped materials like our fibers will result only in approximate values. The size registered for the fibers will depend on their orientation in the fluid. Considering the tendency of agglomeration of cellulose fibers in spherical aggregates and the lack of adequate method for fibers size estimation, we used this analysis for internal comparisons.

\section{PVA composites characterization}

Mechanical behavior of composite films at room temperature was tested in tensile mode according to ISO 527-1:1993 Part 1 and ISO 527-3:1995 Part 3 by an Instron 3382. The Universal Testing Machine was equipped with a video extensometer for strain measurement and with a load cell of $1 \mathrm{kN}$ capacity. The following data: video axial strain at break (elongation at break), tensile stress at break (tensile strength), Young's modulus (tensile modulus), and other optional features, were automatically displayed using the software of the Instron 3382, Bluehill 2 device. Young's modulus on the strain channel with a start value of $0.05 \%$ and an end value of $0.25 \%$ was calculated by the system, applying the least squares fit algorithm to each region between the start and end value selecting the highest slope. The load cell of $1 \mathrm{kN}$ capacity, used for PVA composites tensile properties measurements, has a sensitivity of $0.001 \mathrm{~N}$.

Test specimens were cut to $110 \mathrm{~mm}$ (length) x $10 \mathrm{~mm}$ (width) x $0.035-0.045 \mathrm{~mm}$ (thickness) from the films maintained in desiccators and tested immediately after being removed from the dessicator. 7 specimens were tested for each sample. The conditions of mechanical testing were $50 \%$ relative humidity $(\mathrm{RH})$ and a temperature of $23^{\circ} \mathrm{C}$. Tensile modulus was determined at a crosshead speed of $2 \mathrm{~mm} / \mathrm{min}$, and tensile strength and elongation at $10 \mathrm{~mm} / \mathrm{min}$. Lower crosshead speed was necessary for correct determination of tensile modulus as stipulated by ISO 527 Part 1.

Differential scanning calorimetry (DSC) and thermogravimetric analysis (TGA) were performed on a SDT Q600 V20.9 from TA Instruments under helium flow (100 $\mathrm{mL} / \mathrm{min}$ ). The samples were dried for $24 \mathrm{~h}$ at $40{ }^{\circ} \mathrm{C}$ before testing. The samples weighing between 5 and $10 \mathrm{mg}$ were packed in aluminium pans and placed in the DSC cell and were tested from the ambient temperature to $600{ }^{\circ} \mathrm{C}$ at a heating rate of $10^{\circ} \mathrm{C} / \mathrm{min}$. The DSC glass transition temperature $\left(T_{g}\right)$ was taken at the onset of the glass transition 
endotherm, while the melting temperature $\left(T_{m}\right)$ was taken as the peak temperature of the melting endotherm. The onset degradation temperature $\left(T_{o n}\right)$ was determined as the temperature corresponding to the crossover of tangents drawn on both sides of the decomposition trace, and the temperature of the maximum weight loss rate $\left(T_{d}\right)$ was taken as the peak temperature of the degradation endotherm. The degree of crystallinity $\left(X_{c}\right)$ of the PVA component in the composites was obtained as follows,

$$
X_{c}=\frac{\Delta H_{f}}{w * \Delta H_{0}} * 100
$$

where $\Delta H_{f}$ and $\Delta H_{o}$ are the heats of fusion for PVA composites and $100 \%$ crystalline PVA, respectively, and $w$ is the mass fraction of PVA in the composite. $\Delta H_{o}$ was taken to be $150 \mathrm{~J} / \mathrm{g}$ (Lu et al. 2008).

\section{RESULTS AND DISCUSSION}

\section{Cellulose Fibers Characterization}

The appearance of supernatant samples U1 through U4 one week after they were prepared is shown in Fig. 1. Different degrees of turbidity are visible in Fig. 1, indicating the highest light scattering for sample U4 and the weakest for sample U1, corresponding to different nanofibrillation degrees by applying different ultrasonication conditions.

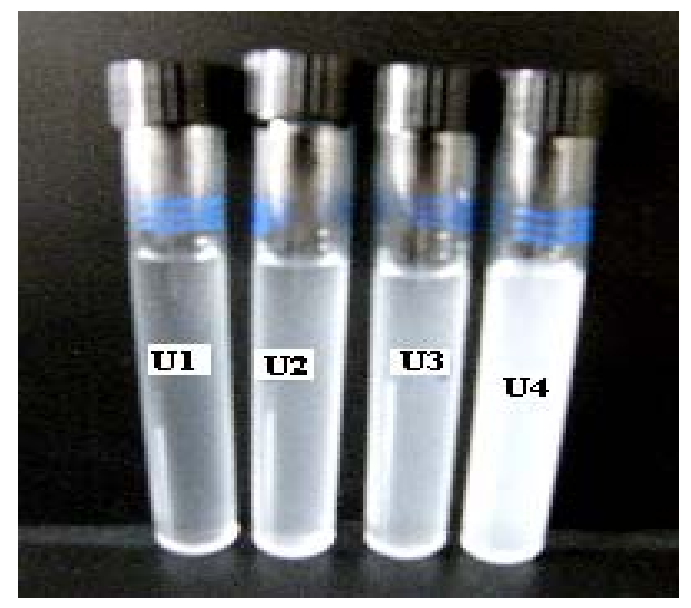

Fig. 1. Cellulose nanofibers (U1 ...U4 samples) obtained by ultrasonication treatment

The presence of turbidity in the supernatant after one week is a strong indication of the presence of cellulose nanofibers, as observed by Chen et al. (2010). Moreover, Petersson et al. (2007) as well as Bondenson et al. (2006) obtained cellulose nanofibers by applying several cycles of centrifugation, noting that the supernatant remained turbid, considered the persistence of turbidity as a sure proof of the presence of nanocellulose 
fibers in the supernatant. The turbidity increased from U1 to U4 with the increase of power and time of sonication, showing the effectiveness of the sonication process.

The yield of the cellulose nanofibers was determined as a percentage of the cumulative dry weight of the supernatant (S1) and the sediment (S2). The yield of cellulose nanofibers $(\mathrm{Y})$ was calculated as the ratio $\mathrm{S} 1 \times 100 /(\mathrm{S} 1+\mathrm{S} 2)$, with the average of three determinations reported in Table 2.

The highest content of cellulose nanofibers was obtained for sample U4, an intermediate content for samples U2 and U3, and the lowest yield in the case of sample U1. The results are consistent with the observations of turbidity, as specified above.

\section{Table 2. Yield of Cellulose Fibers}

\begin{tabular}{|c|c||}
\hline SAMPLE & $\begin{array}{c}\text { Y } \\
{[\%]}\end{array}$ \\
\hline U1 & 7.8 \\
\hline U2 & 14.3 \\
\hline U3 & 17.7 \\
\hline U4 & 27.6 \\
\hline
\end{tabular}

The temperature of cellulose fiber suspensions after the ultrasonication process changed depending on the power and time of ultrasonication, higher temperature being observed at higher values of the power and time of ultrasonication. An increase of the sample temperature was also obtained by Wang and Cheng (2009) when high intensity ultrasonication was applied to different cellulose sources.

\section{FE-SEM analysis}

FE-SEM micrographs of cellulose fibers U1 through U4 are shown in Fig. 2. The FE-SEM images demonstrate the effectiveness of the MCC defibrillation process, fibers with a diameter ranging from a couple of nanometers to $150 \mathrm{~nm}$ being observed.

Several differences were detected between the samples obtained with the application of different ultrasonic conditions. In the case of samples prepared with the lower ultrasonication power and the lower time of sonication (U1), pieces of undefibrilated MCC and many fibers with a diameter of 70 to $150 \mathrm{~nm}$ were observed. When a higher time of sonication was applied (U2), no pieces of undefibrilated MCC were detected, and the diameters of fibers were smaller, from 10 to $100 \mathrm{~nm}$.

Between the samples prepared at higher ultrasonication power (U3 and U4) there were no significant differences. In the images one can see nanofibers of cellulose with very small dimension $(<20 \mathrm{~nm})$. Uniform dimensions can be noticed in these samples, especially in the case of sample U4. 


\section{bioresources.com}
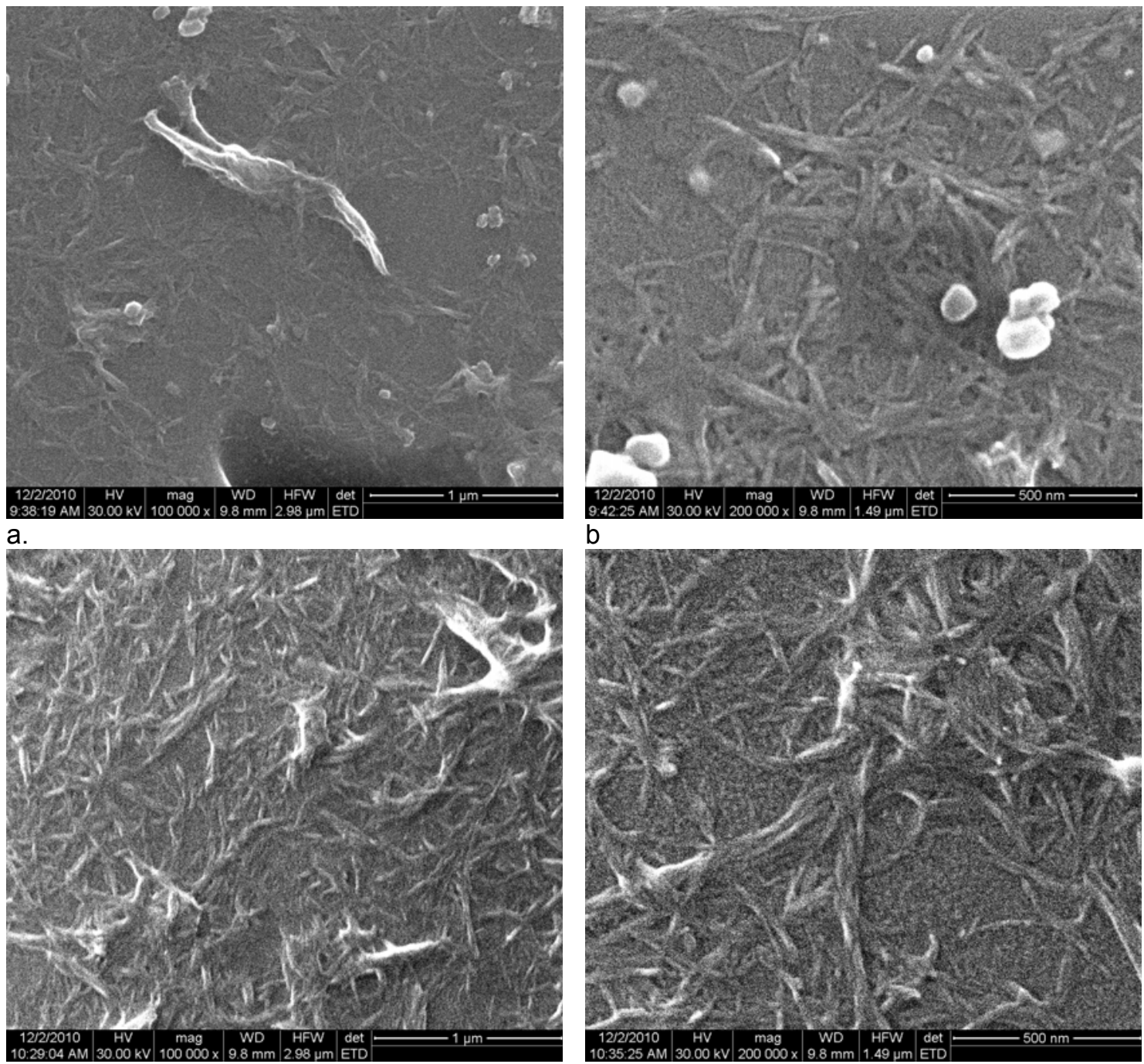

c.

d.

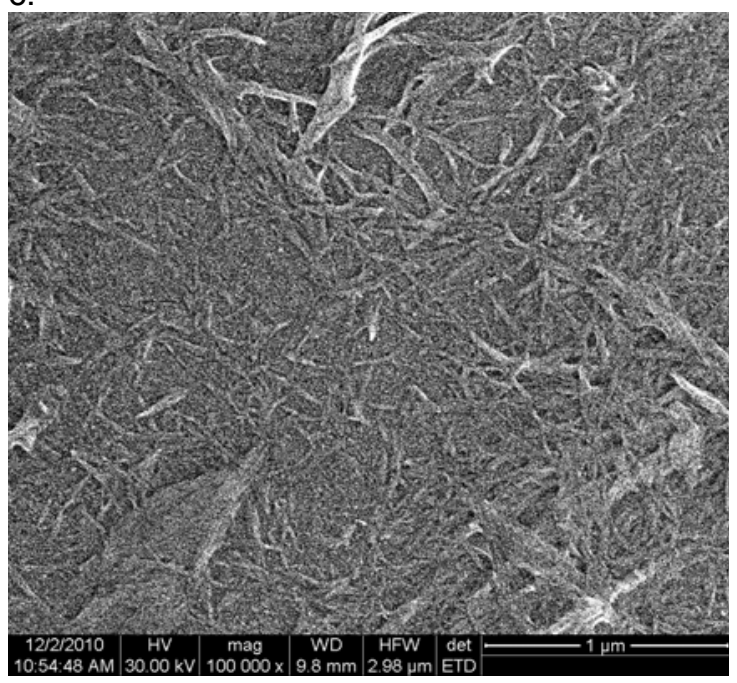

e.

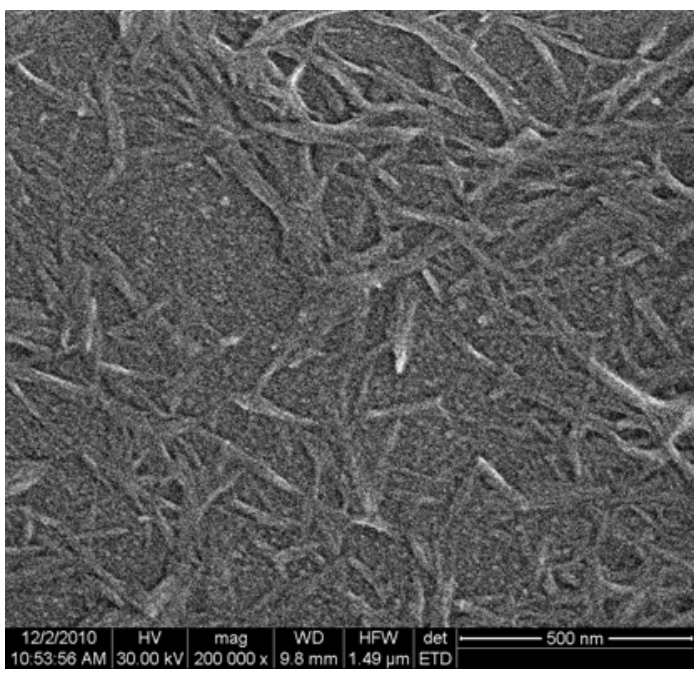

f.

Frone et al. (2011). "Cellulose nanofibers, PVA films," BioResources 6(1), 487-512. 


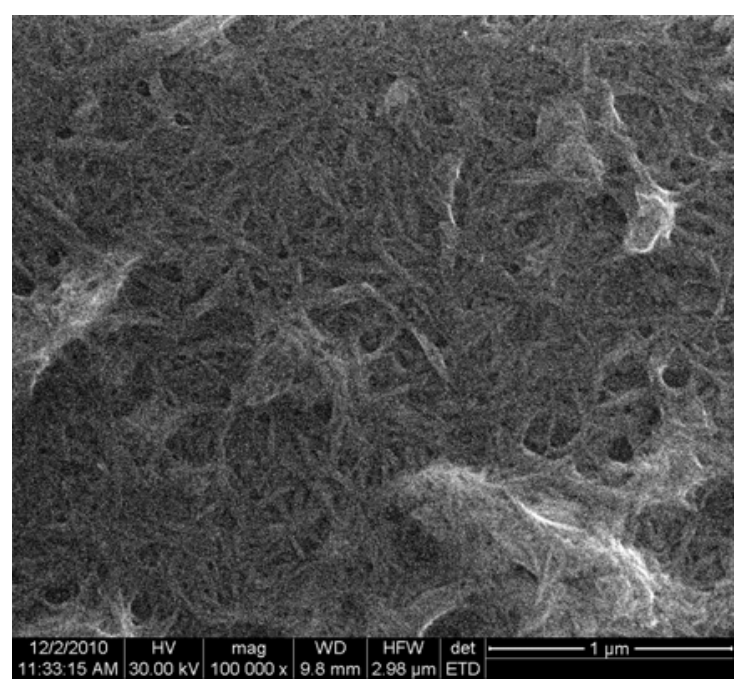

g.

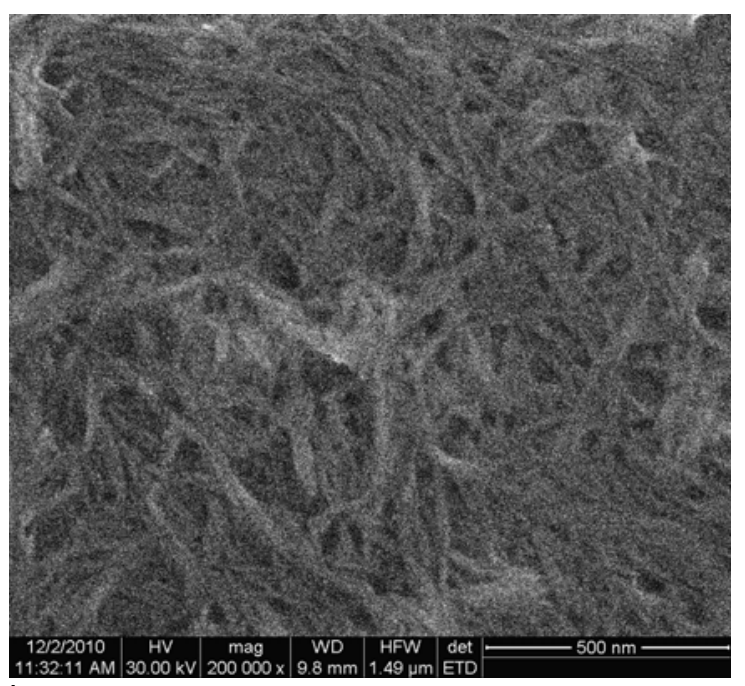

$\mathrm{h}$.

Fig. 2. FE-SEM images of cellulose nanofiber samples $U 1$ - U4 obtained by ultrasonication: a, c, e, $g$ - magnitude of 100000; b, d, f, h - magnitude of 200000;

All the samples show a network like structure formed of cellulose nanofibers. At higher ultrasonication power the network seemed more compact because of the uniform dimensions of the fibers. The high aspect ratio of cellulose nanofibers regardless of the applied conditions can also be observed in Fig. 2.

\section{AFM investigation}

The structure and size distribution of U1 and U4 cellulose nanofibers, analyzed by AFM, are shown in Fig. 3.
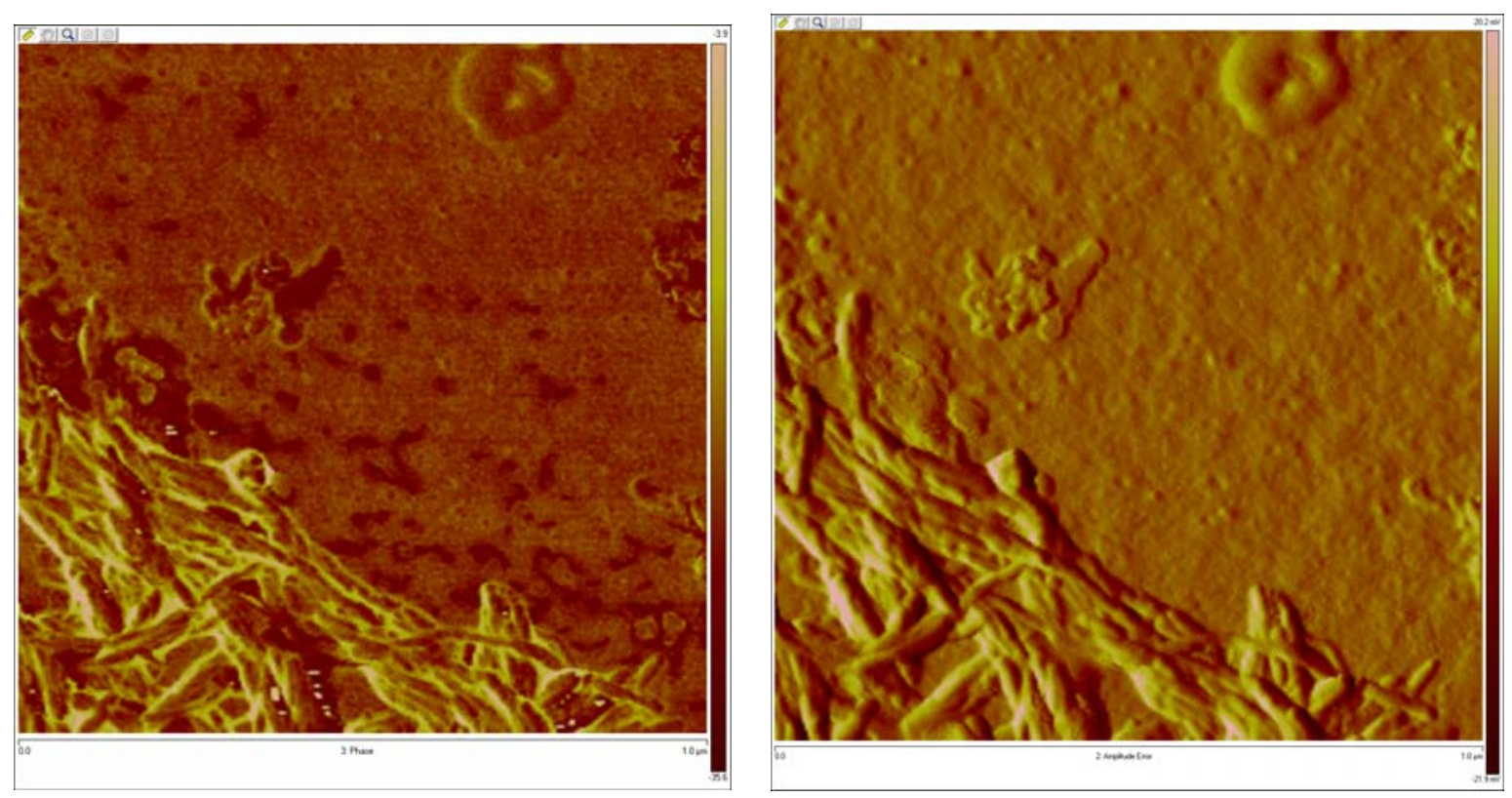

Fig. 3a. Phase and amplitude AFM images of cellulose nanofiber samples U1: $1.0 \mu \mathrm{m} \times 1.0 \mu \mathrm{m}$ 

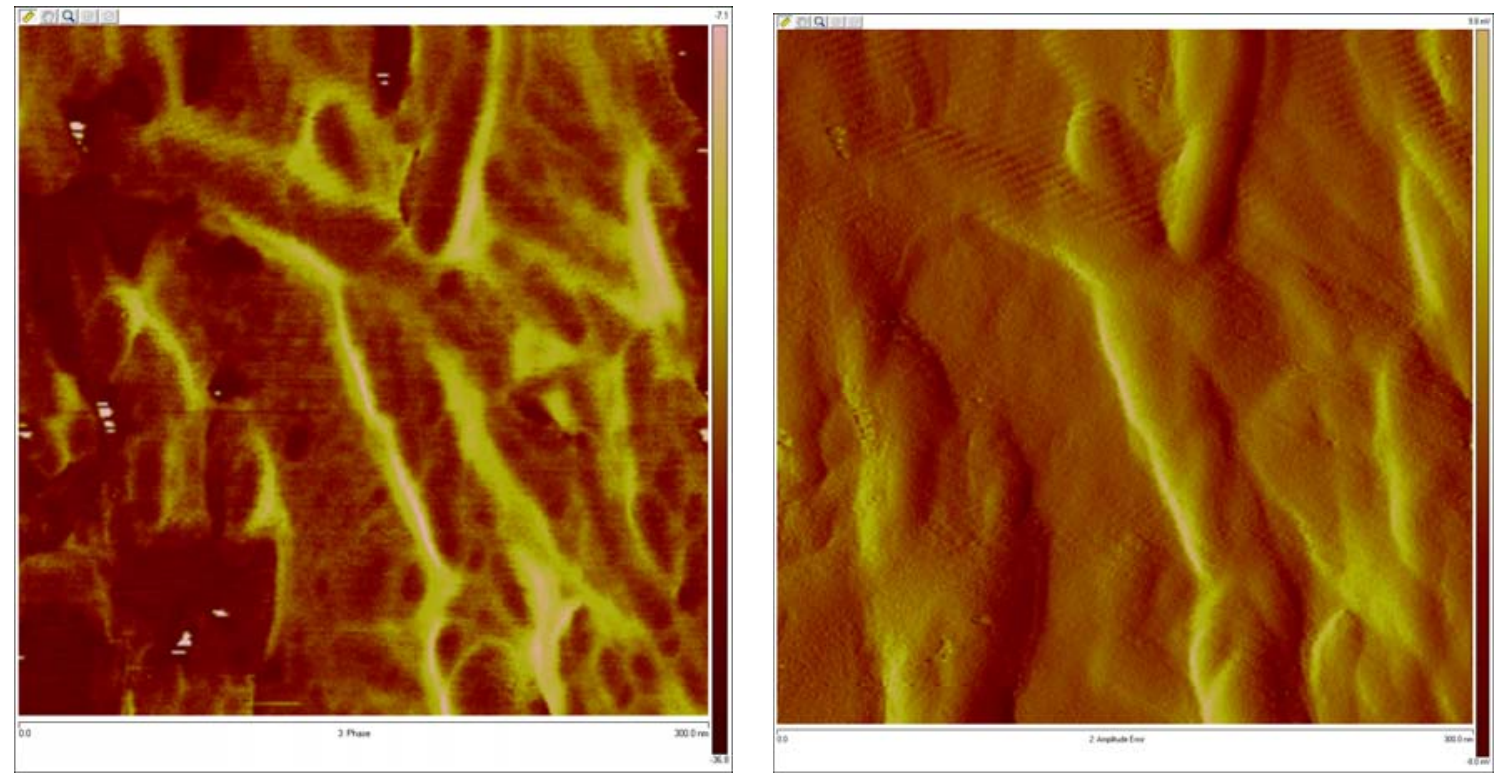

Fig. 3b. Phase and amplitude AFM images of cellulose nanofiber samples U1: $300 \mathrm{~nm} \times 300 \mathrm{~nm}$
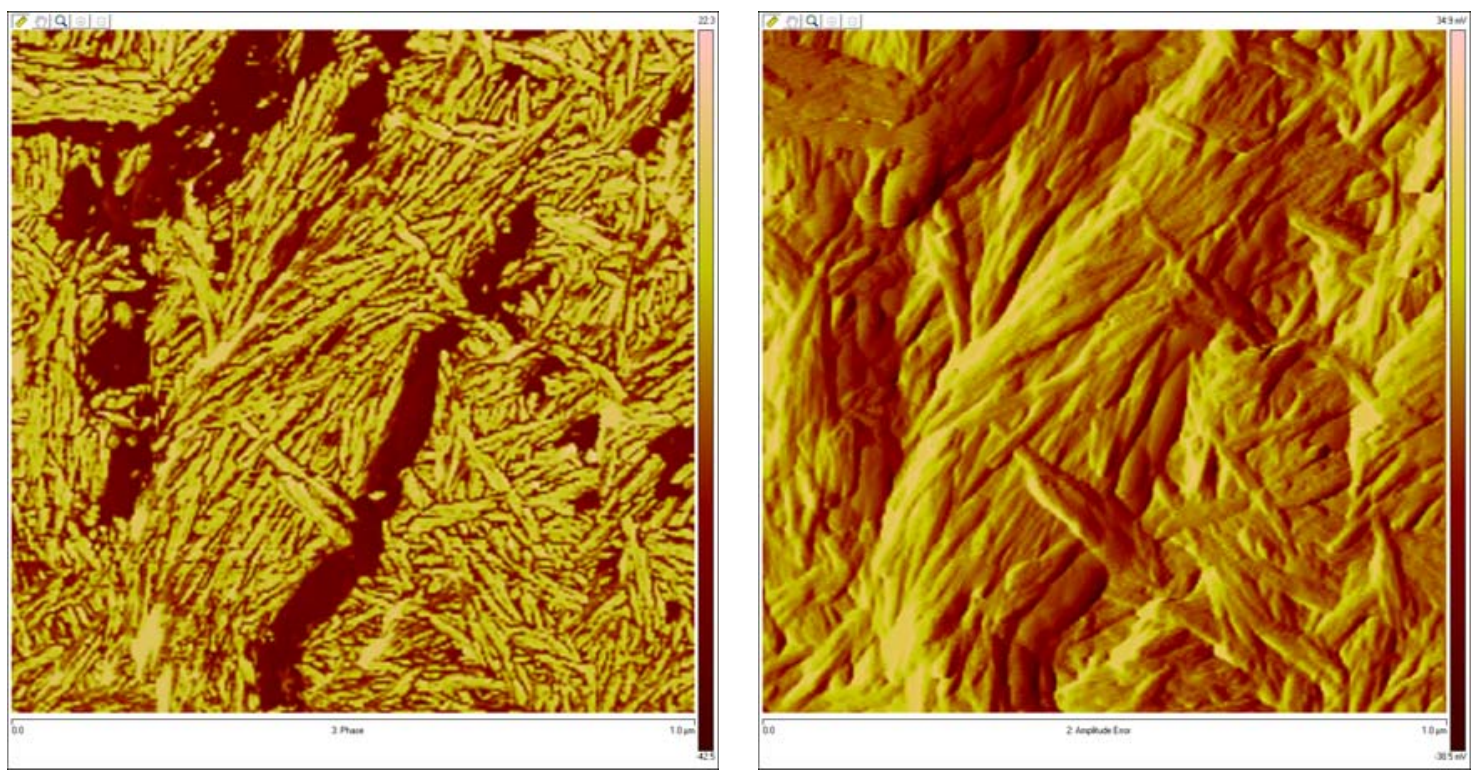

Fig. 3c. Phase and amplitude AFM images of cellulose nanofiber samples $U 4: 1.0 \mu \mathrm{m} \times 1.0 \mu \mathrm{m}$

The images shown in Fig. 3a and 3c have a larger scanning area of $1.0 \mu \mathrm{m} \times 1.0$ $\mu \mathrm{m}$, while the images shown in Fig. $3 \mathrm{~b}$ and $3 \mathrm{~d}$ have a scanning area of $300 \mathrm{~nm} \times 300 \mathrm{~nm}$. The phase and amplitude images of cellulose nanofibers show the presence of bundles of long cellulose fibers in the nanometer scale in both cases, but the features of U1 and U4 nanofibers shown in these images are not identical. 

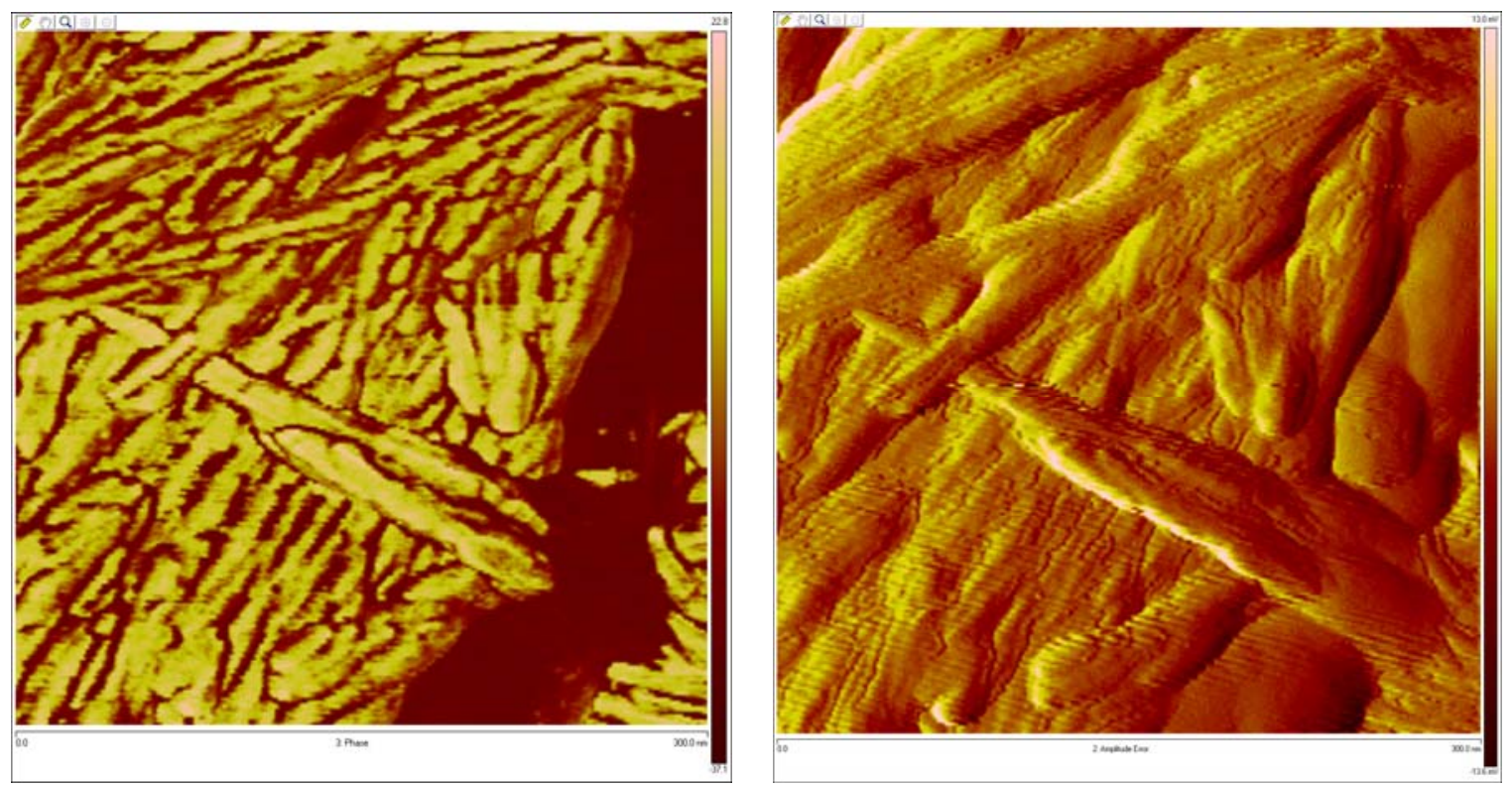

Fig. 3d. Phase and amplitude AFM images of cellulose nanofiber sample U4: $300 \mathrm{~nm} \times 300 \mathrm{~nm}$

The U1 nanofibers appear larger in diameter than U4, and nonfibrillar inclusions can also be observed in the first case. The diameter of U1 fibers, determined based on AFM height images, was in a range from $22.0 \mathrm{~nm}$ to126.6 nm with an average of $39.0 \pm$ 15.3, and the diameter of U4 fibers, in a range from $11.4 \mathrm{~nm}$ to $31.9 \mathrm{~nm}$ with an average of $18.2 \pm 5.8$. The measurements were made using software in which the height of the nanofibers was determined. These results correlate well with the FE-SEM measurements.

\section{XRD analysis}

The X-ray diffraction pattern of MCC is shown in Fig. 4. The diffraction peaks, characteristic to cellulose I $\left(17.3^{\circ}, 18.9^{\circ}, 26.2^{\circ}\right)$, are similar to those mentioned in the literature (Park et al. 2010), considering the wavelength $\lambda=1.79021 \AA$ of Co K $\alpha$ radiation used in the test. A good concordance between the experimental values and the calculated curve (the sum of the peaks intensities resulted from deconvolution), are clearly observed in Fig. 4. Figure 5 shows $d_{002}$ values, as resulted after deconvolution, and emphasizes the effectiveness of the curve fitting. The better resolution of the peaks was favored by the $\mathrm{Co} \mathrm{K} \alpha$ radiation, as used in these tests.

In some cases reported in the literature, the application of ultrasonic treatment, alone or with other treatments, led to an increase of cellulose crystallinity. Cheng et al. (2010) reported the increase of cellulose fibers crystallinity from $35 \%$ in case of untreated lyocell fibers to $43-44 \%$ (ultrasonicated fibers).

An attempt was made to determine whether this behavior is effective in the present case. Initially, the method of Cheng et al. (2010) was used to determine the crystallinity $(C I)$,

$$
C I=\frac{I_{C}}{I_{C}+I_{A}}
$$




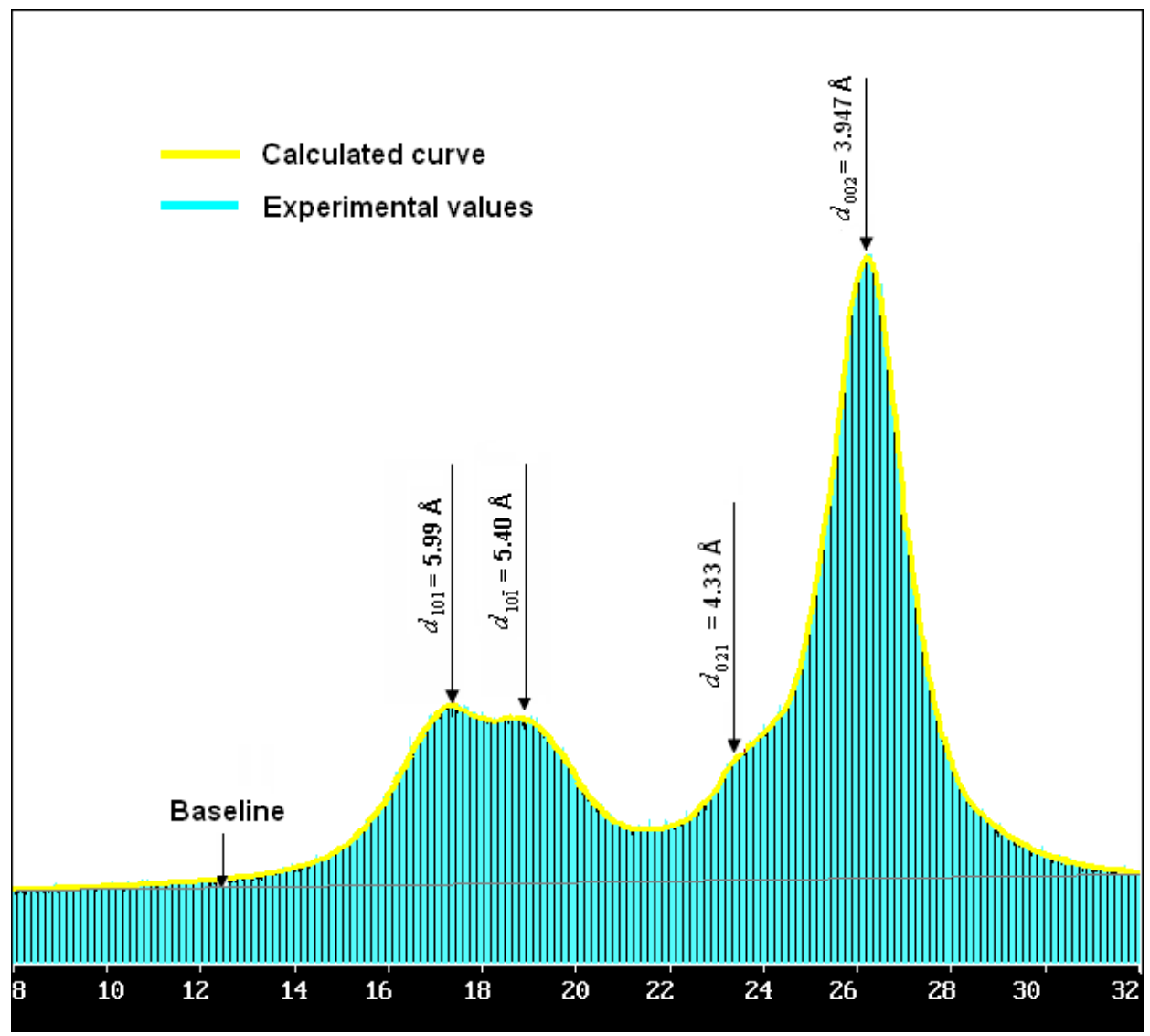

Fig. 4. MCC X-ray diffractogram - experimental values and calculated curve

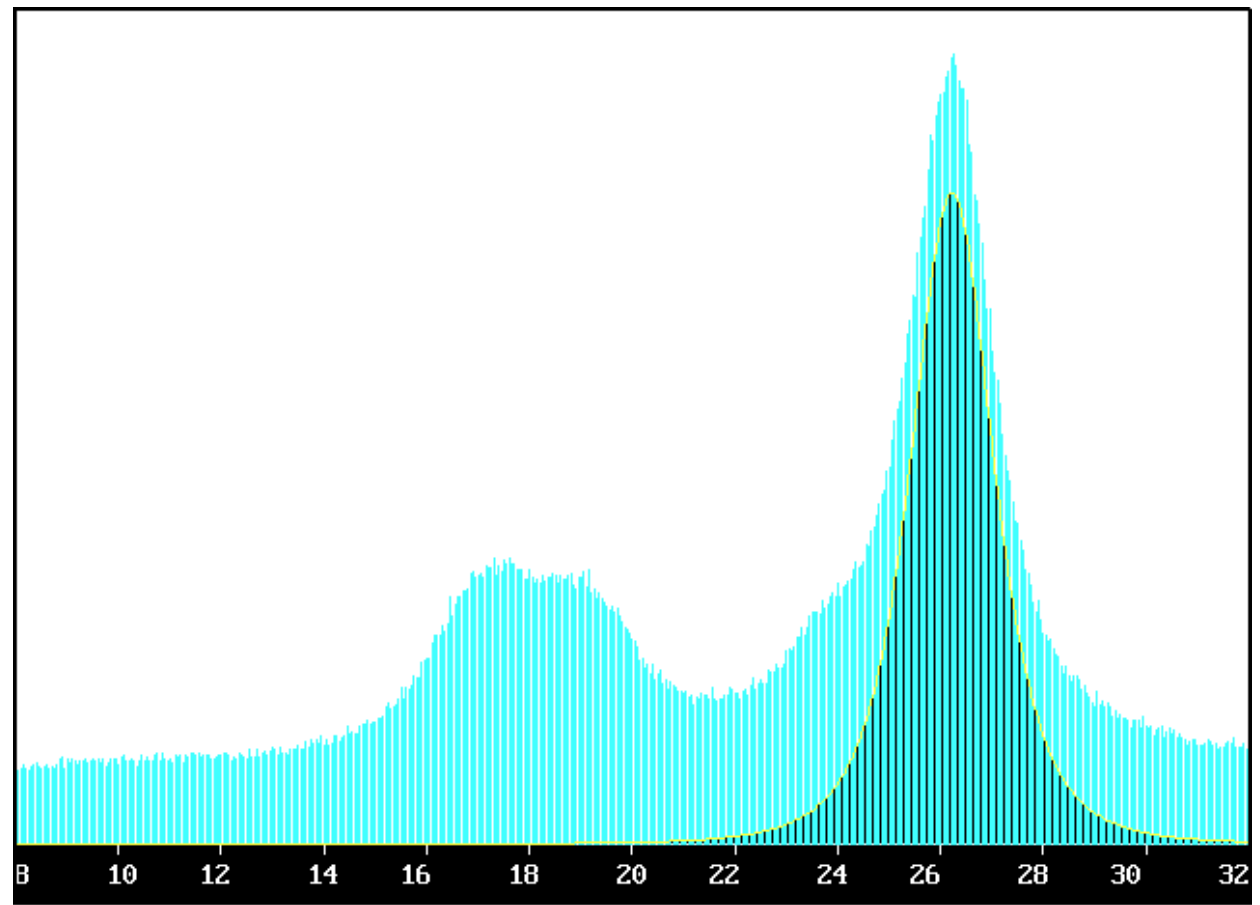

Fig. 5 Deconvolution method in case of 002 peak (MCC) 
where $I_{C}$ and $I_{A}$ are the integrated intensities due to the crystalline phase and amorphous phase, respectively, as resulted from the deconvolution.

The reproductibility of the results was not satisfactory $( \pm 3 \%)$ because of the pour reproductibility in the case of $I_{A}$. Better results (Table 3) were obtained using the whole area under the diffraction curve $( \pm 1 \%)$ instead of the sum of $I_{C}$ and $I_{A}$. In case of this last method the results were shifted to higher values (2-3\%), but the better reproductibility was able to provide a better correlation between the crystallinity evolution and the ultrasonic parameters.

Table 3. XRD Data of Cellulose Fibers Obtained by Ultrasonic Treatment

\begin{tabular}{|c|c|c|c|c||}
\hline Sample & $\boldsymbol{C l}$ & $\begin{array}{c}\boldsymbol{d}_{002} \\
{[\AA]}\end{array}$ & $\begin{array}{c}\boldsymbol{\beta}_{002} \\
{\left[{ }^{0}\right]}\end{array}$ & $\begin{array}{c}\bar{D}_{002} \\
{[\AA]}\end{array}$ \\
\hline MCC & 89.7 & 3.947 & 2.33 & 45.4 \\
\hline U1 & 88.7 & 3.948 & 2.32 & 45.4 \\
\hline U2 & 88.5 & 3.947 & 2.32 & 45.5 \\
\hline U3 & 90.1 & 3.945 & 2.31 & 45.7 \\
\hline U4 & 89.0 & 3.945 & 2.33 & 45.2 \\
\hline
\end{tabular}

Unlike other reported results, no important differences in terms of crystallinity between MCC and ultrasonicated samples (U1 - U4) can be observed in Table 3, similar values being obtained within the measurement errors $(89.2 \pm 0.8)$.

The X-ray diffractograms of cellulose samples U1 through U4 are shown in Fig. 6. They are very similar to that of MCC, showing little influence in the ultrasonic parameters with respect to the crystalline phase of cellulose. The inter-planar distances $\left(d_{002}\right)$, integrated half width of the crystalline peak $(002)\left(\beta_{002}\right)$, and the crystallite dimensions $\left(\bar{D}_{002}\right)$ were calculated for all the samples using $d_{002}$ values obtained from deconvolution, and are presented in Table 3.

The median crystallite dimension $\left(\bar{D}_{002}\right)$ was determined from the Scherrer equation,

$$
\bar{D}_{002}=\frac{\lambda}{\beta_{c} \cos \theta}
$$

where $\lambda=1.7902 \AA, \beta_{c}=\sqrt{\beta^{2}-\beta_{i}^{2}}$ ( $\beta_{i}=$ instrumental half width), and $\theta$ is the diffracttion angle $\left(13.11^{\circ}\right)$. Both the inter-planar distances $d_{002}$ and the integrated half width $\beta_{002}$ remained unchanged within the measurement errors, $\pm 0.05 \%$ and $\pm 0.5 \%$, respectively. This observation highlights the absence of significant changes in the crystalline structure of cellulose after the applied ultrasonication treatment. 


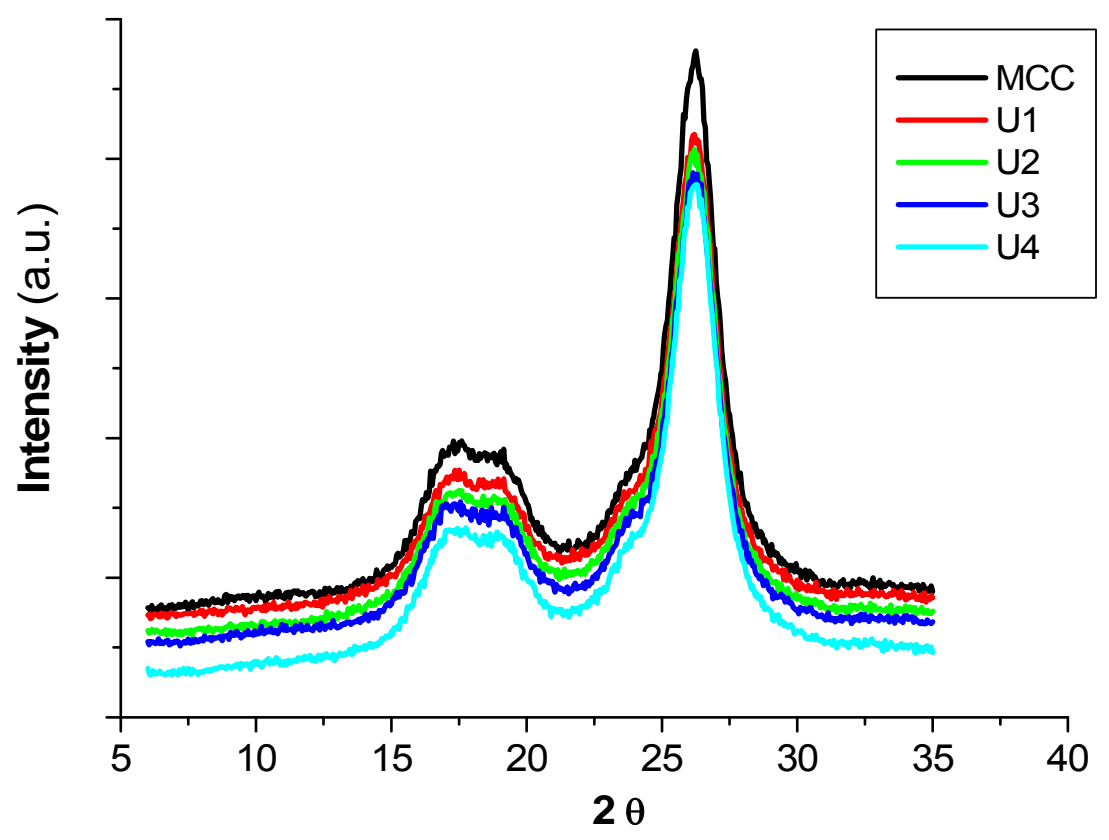

Fig. 6 X-ray diffraction patterns of MCC and cellulose nanofibers

\section{DLS analysis}

DLS analysis results showed different sizes of cellulose fibers aggregates detected by light scattering for different ultrasonic treatments applied (Table 4).

Table 4. DLS Data of Cellulose Fibers Aggregates Obtained by Ultrasonic Treatment

\begin{tabular}{||c|c|c|c||}
\hline \hline Sample & $\begin{array}{c}\text { Medium diameter of } \\
\text { cellulose aggregates, } D_{m} \\
\text { [nm] }\end{array}$ & $\begin{array}{c}D_{m 1} \\
\text { peak 1 } \\
\text { [nm] }\end{array}$ & $\begin{array}{c}D_{m 1} \\
\text { peak 2 } \\
{[\mathrm{nm}]}\end{array}$ \\
\hline U1 & 3040 & 385.5 & - \\
\hline U2 & 2120 & 233.6 & - \\
\hline U3 & 860.9 & 1107 & 134.8 \\
\hline U4 & 989.2 & 1045 & 229.4 \\
\hline
\end{tabular}

DLS analysis data revealed aspects of the defibrillation process of MCC, which occurred with different intensities in all the four trials. Doubling of the ultrasonic power was significantly more effective in MCC defibrillation than doubling the time of ultrasonification. The samples with the smallest size of nanofibers aggregates were U3 and U4, obtained with the highest ultrasonic power of $400 \mathrm{~W}$ (Fig. 7). Larger diameters than those determined for U1 and U4 samples in FE-SEM and AFM analysis were obtained in DLS measurements, because of the rapid aggregation of cellulose nanofibers in water suspension. 


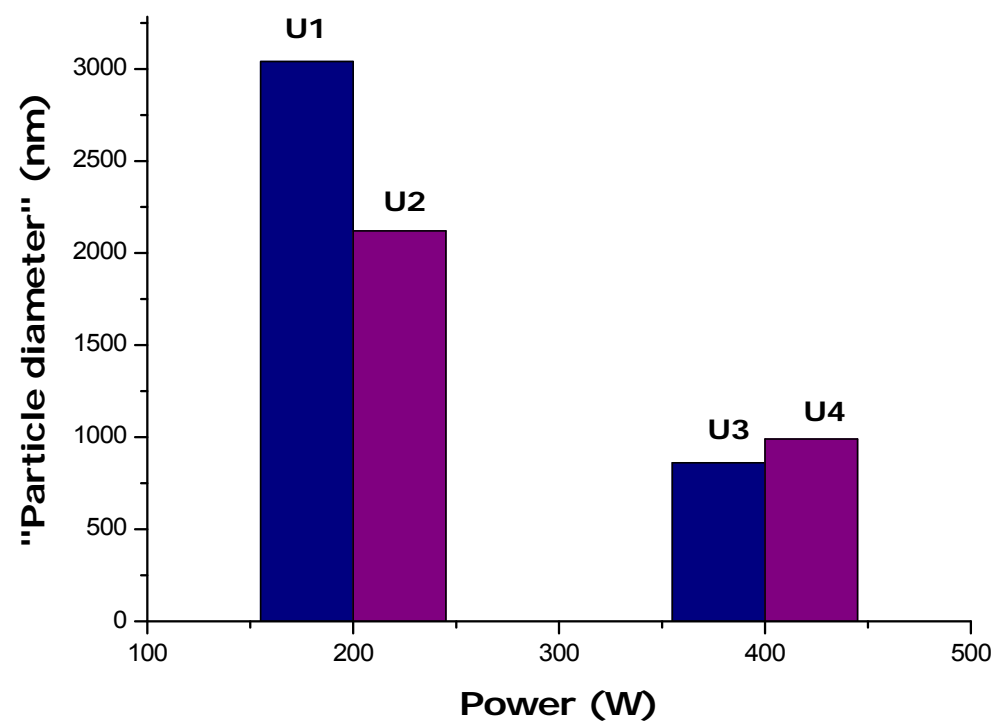

Fig. 7. Variation of DLS medium diameter of cellulose aggregates with the ultrasonic power

\section{Composite Characterization}

The resulting PVA/cellulose fibers films of about $0.04 \mathrm{~mm}$ showed transparency and flexibility. On visual inspection, there are no apparent differences between the PVA films and the PVA films containing 5\% cellulose fibers (Fig. 8).

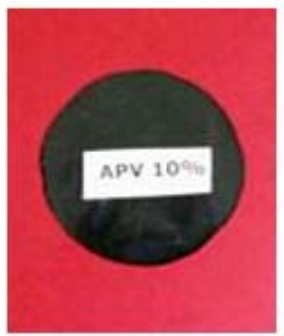

$\mathbf{a}$

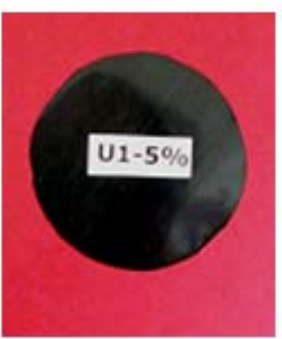

b

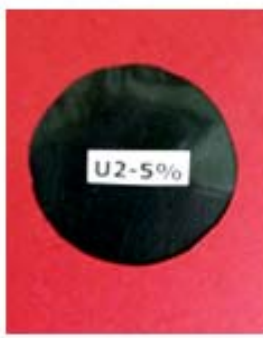

C

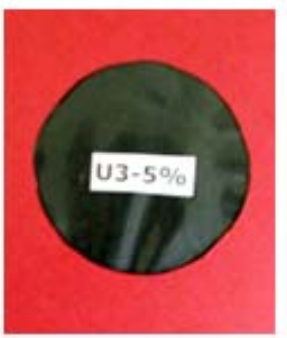

d

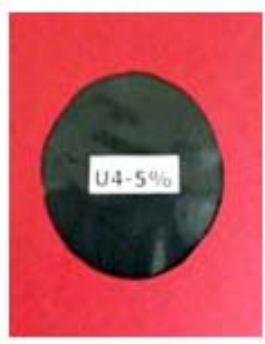

e

Fig. 8. PVA films containing 5\% cellulose nanofibers: a. PVA; b.PVA/U1; c. PVA/U2; d. PVA/U3; e. PVA/U4. For highlighting the transparent nature of the films, they were placed on a black pad with a label containing the name of the sample and were covered with a red frame to be kept uncoiled.

\section{Mechanical properties}

The tensile strength, elongation at break, and elastic modulus of the PVA/ cellulose fiber composite films compared with those of unreinforced PVA film are shown in Figs. 9 - 11. The standard deviation divided by the mean was $4 \%$ for tensile strength and modulus and 7\% for elongation at break. A significant increase in tensile strength with increased filler loading was observed in the case of PVA/U1 through PVA/U4 composites, the most important increases being observed at low filler loading (Fig. 9). 


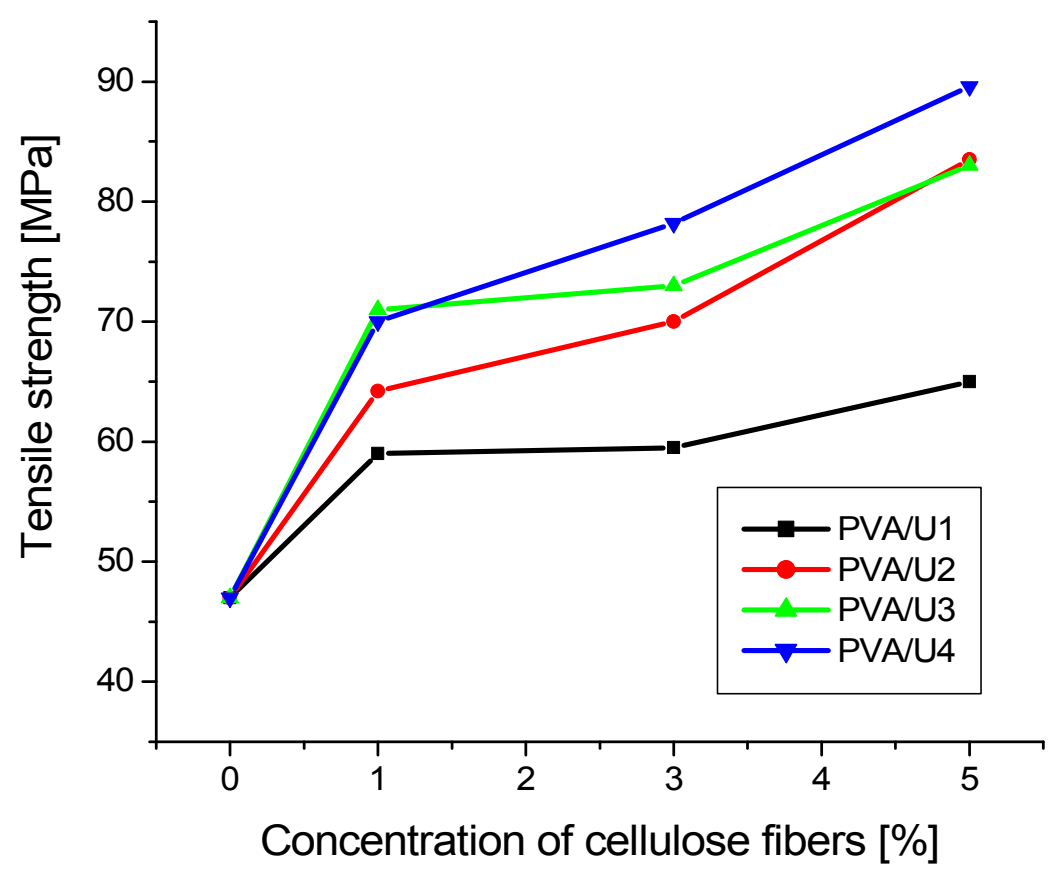

Fig. 9. Tensile strength of neat PVA and cellulose fibers reinforced PVA films

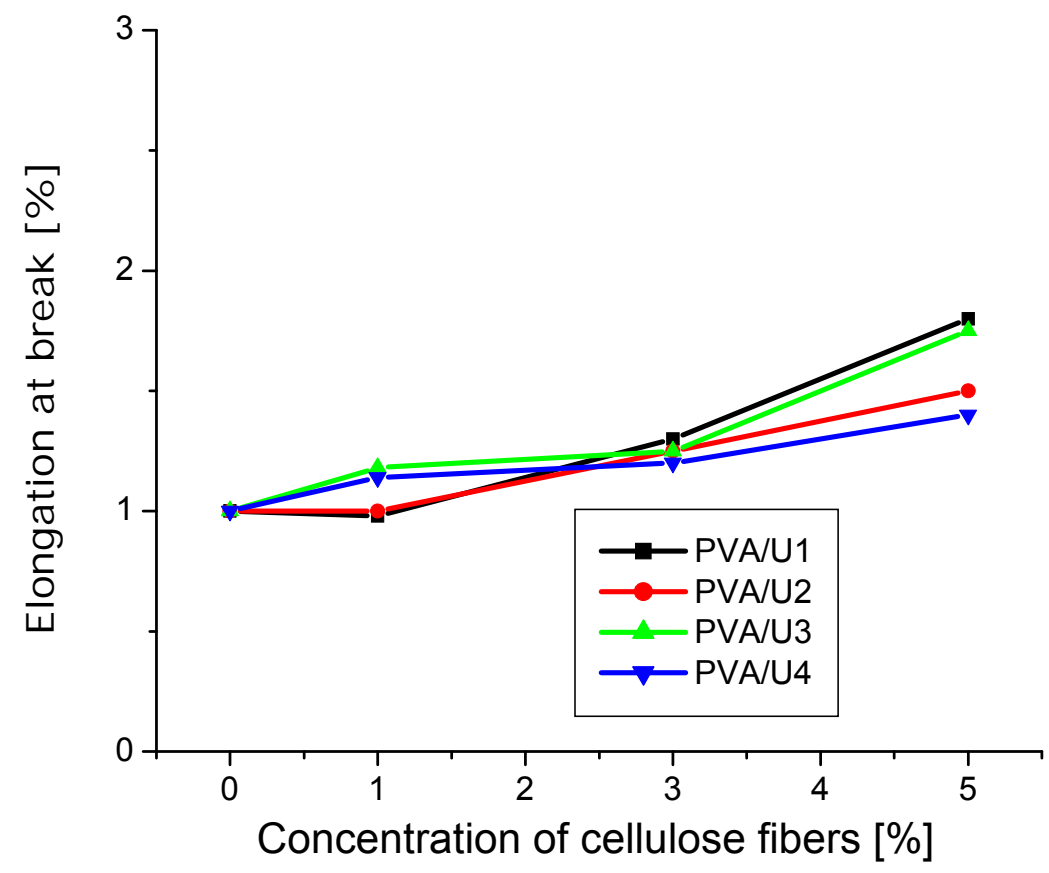

Fig. 10. Elongation at break of neat PVA and cellulose fibers reinforced PVA films 


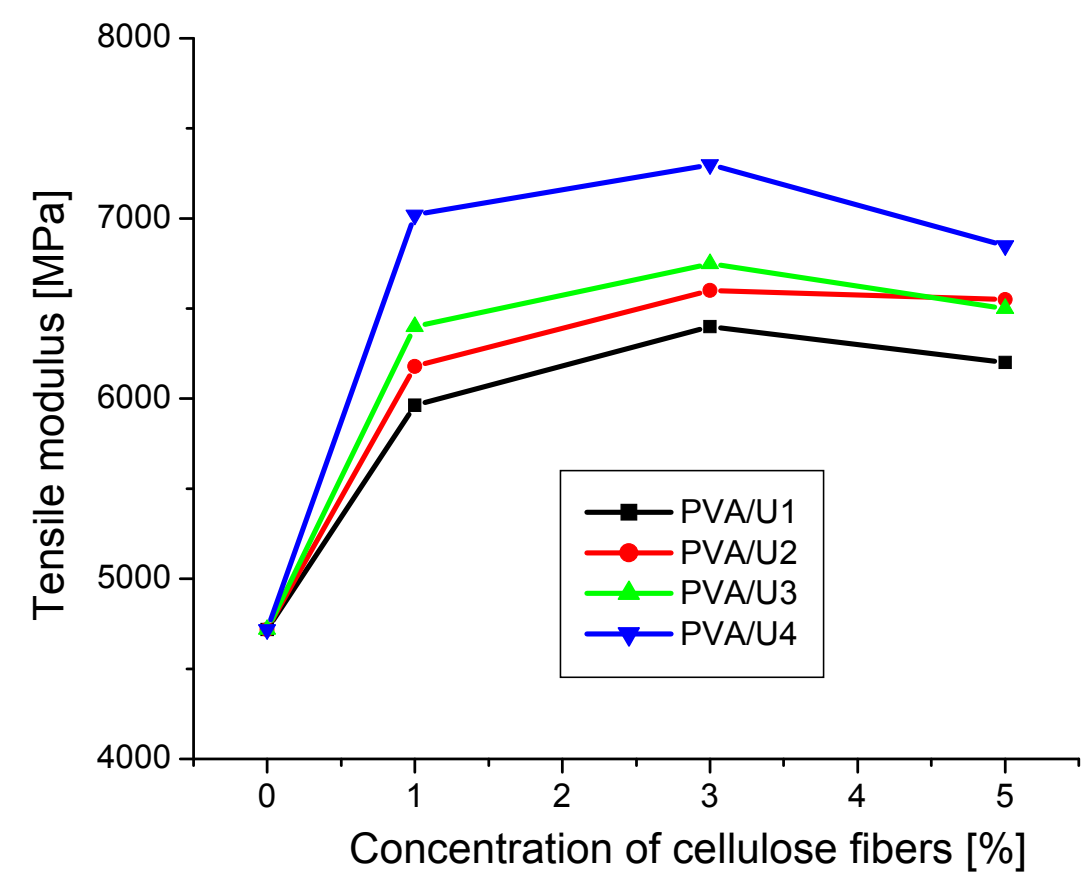

Fig. 11. Tensile modulus of neat PVA and cellulose fibers reinforced PVA films

The highest improvement of tensile strength with respect to PVA was obtained for PVA/U4 composites (almost 90\% for $5 \mathrm{wt} \% \mathrm{U} 4$ in PVA) and the smallest for PVA/U1 composite (38\% for $5 \mathrm{wt} \% \mathrm{U1}$ in PVA). An increase of the tensile strength in the sequence $\mathrm{U} 1<\mathrm{U} 2<\mathrm{U} 3<\mathrm{U} 4$ was observed for almost all cellulose fiber concentrations. As observed in Fig. 9, loading PVA with cellulose nanofibers resulted in a strong reinforcing effect, favored by the increased interfacial area and more active surface in the case of smaller size cellulose fibers, as revealed by FE-SEM (U4 and U3 against U1 and U2). Elongation at break of PVA composites was less affected by cellulose fibers addition (Fig. 10). A small increase of the elongation at break was observed for all four types of PVA composites at 5\% fiber loading. A better behavior was observed in the case of PVA filled with 5\% U1 and U3 in comparison to U2 and U4 nanofiber containing composites. An explanation for this behavior could be the influence of the time of sonication on the length of the fibers, a higher time of sonication in the case of U2 and U4 samples inducing a reduction of fiber's length, but this hypothesis must be verified by further investigations.

The values of composites tensile modulus showed (Fig. 11) an important increase at lower loading of U1 through U4 cellulose nanofibers (1 wt.\%) in PVA and no significant increase for higher filler amounts (5 wt.\%). The highest increase of 55\% with respect to PVA was observed for 3\% U4 filler loading in PVA. An increase of the tensile modulus in the sequence $\mathrm{U} 1<\mathrm{U} 2<\mathrm{U} 3<\mathrm{U} 4$ was observed for almost all cellulose fiber concentrations. 
The enhancement of mechanical properties of PVA/nanocellulose composite films by comparison with neat PVA resulted from the good adhesion at the filler/matrix interface. The hydrogen bonding between the $\mathrm{OH}$ groups of cellulose fibers and similar groups of the PVA matrix is the main reason for improved adhesion between the phases, which resulted in improved mechanical properties. Lee et al. (2009) explained an increase of about $70 \%$ in the elastic modulus and up to $55 \%$ in the tensile strength by the intermolecular forces between cellulose fibers and the PVA matrix. Also, the improvement of tensile properties of cellulose whiskers reinforced PVA was attributed by Roohani et al. (2008) to the strong interactions between PVA matrix and cellulose whiskers via hydrogen bonding.

Better mechanical properties were obtained in the case of PVA composites containing smaller size fibers (U3 and U4) against those containing larger size fibers (U1 or U2). The higher interface area and the larger probability of hydrogen bonding in the case of smaller size fibers could explain the higher reinforcing effect observed. Weaker values of tensile modulus obtained for higher concentrations of fibers $(5 \%)$ can be generated by several factors. Among these factors, the agglomeration of nanofibers at higher concentration, the influence of water, and PVA crystallinity are the most important in our opinion.

\section{Thermal properties}

The thermal properties of neat PVA and PVA composites films containing 5\% $\mathrm{U} 1, \mathrm{U} 2, \mathrm{U} 3$, and $\mathrm{U} 4$ fibers were determined from DSC and TGA thermograms. The main thermal transitions, glass transition temperature $(T g)$ and melting point $(T m)$, and other characteristic temperatures were evaluated and compared with those of the neat PVA. DSC results of PVA composites containing $5 \mathrm{wt} \%$ of cellulose fibers, U1 through U4 types, are shown in Fig. 12.

PVA exhibited an endotherm close to $57^{\circ} \mathrm{C}\left(57.2^{\circ} \mathrm{C}\right)$ corresponding to the glass transition temperature of PVA. Similar values of the glass transition temperature of PVA have been reported (Zhang et al. 2010; Peresin et al. 2010; Hu and Chen 2010). The glass transition temperature of PVA depends on its characteristics (hydrolysis degree, polymerization degree, and others) and, particularly, on the moisture content, a broad interval of temperatures of 58 to $85{ }^{\circ} \mathrm{C}$ being reported for this characteristic (Wiria et al. 2008). Tg decreases as the humidity content increases owing to the well-known plasticizing effect of water molecules for PVA chains (Roohani et al. 2008).

No significant changes in $T_{g}$ value were observed in the case of PVA composites containing $5 \mathrm{wt} \% \mathrm{U}$ fibers, as shown in Table 5 . This behavior can be explained by the small size of the fibers, which did not cause massive breaks of hydrogen bonds in PVA. The expected interactions between these cellulose fibers and PVA did not alter the supramolecular structure of the amorphous phase and, as a result, the rubbery properties and the increase of the mobility of the macromolecules appeared at about the same temperature. Nevertheless, it seemed that these newly formed interactions were not strong enough to slow the chain mobility associated with glass transition, since the $T_{g}$ values measured on PVA/U composite samples were close to that of neat PVA. 


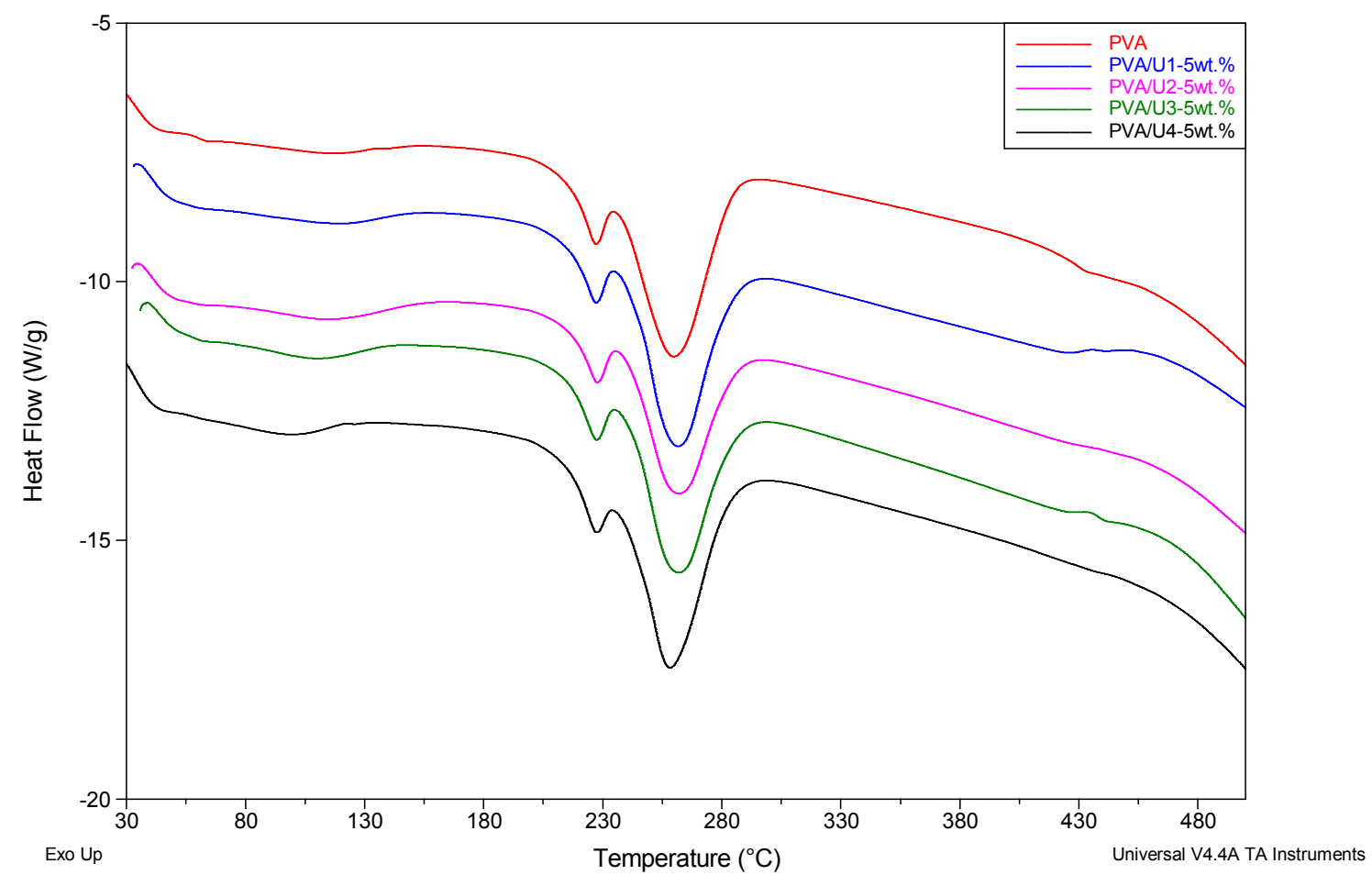

Fig. 12. DSC diagrams of neat PVA and PVA composites containing $5 \% \mathrm{U} 1, \mathrm{U} 2$, U3, and $U 4$ fibers

Table 5. DSC Data for Neat PVA and PVA Composites Containing 5 wt. $\%$ U Fibers

\begin{tabular}{||l|c|c|c|c||}
\hline \hline Samples & $\begin{array}{c}T_{g} \\
{ }^{0} \mathrm{C}\end{array}$ & $\begin{array}{c}T_{m} \\
{ }^{0} \mathrm{C}\end{array}$ & $\begin{array}{c}\Delta H_{m} \\
\mathrm{~J} / \mathrm{g}\end{array}$ & $\begin{array}{c}X_{c} \\
\%\end{array}$ \\
\hline PVA & 57.2 & 227.1 & 79.3 & 52.9 \\
\hline PVA/5\%U1 & 56.4 & 226.2 & 78.5 & 55.1 \\
\hline PVA/5\%U2 & 56.2 & 226.7 & 76.0 & 53.3 \\
\hline PVA/5\%U3 & 56.9 & 226.4 & 78.4 & 55.0 \\
\hline PVA/5\%U4 & 56.0 & 226.1 & 73.2 & 51.4 \\
\hline \hline
\end{tabular}

PVA exhibited a sharp endothermic curve with a peak at $227.1^{\circ} \mathrm{C}$, as shown in Fig. 12, corresponding to the melting of the crystalline phase of PVA. $T_{m}$ values remained roughly constant for all PVA composites whatever the type of fibers used, but the heat of fusion differed, depending on the filler characteristics.

An increasing trend of the degree of crystallinity was observed for PVA composites containing U1 and U3 fibers. Lu et al. (2008) observed a slight increase of 
PVA crystallinity with a small addition $(<5 \mathrm{wt} . \%)$ of microfibrillated cellulose, and the same phenomena were observed for cellulose whiskers used as reinforcement in starch (Mathew et al. 2002) and carbon nanotubes reinforced PVA composites (Coleman et al. 2004). In all these cases, the increase in crystallinity was explained by the nucleating effect of the nano-sized fillers. In our case, this influence alone cannot explain the different behavior of PVA composites containing U1 and U3 fibers against composites containing U2 and U4 fibers, other factors influencing equally.

Thermogravimetric analysis (TGA) was used to investigate the effect of cellulose fibers on the thermal stability of the composites (Fig. 13).

In thermograms obtained with PVA and PVA composites three main weight loss regions were observed, consistent with other observations (Lee et al. 2009; Qua et al. 2009). All of the samples showed an initial weight loss in the region 70 to $140{ }^{\circ} \mathrm{C}$ attributable to the evaporation of water. Between 2.3 and $3.4 \mathrm{wt} \%$ physically and chemically bound water was detected in neat PVA and PVA composites (Table 6). Physically bound water or free water has a strong plasticizing effect, improving the movement of PVA chains and decreasing the matrix polymer's crystallinity. Also, chemically bound water disrupts the intra- and inter-molecular hydrogen bonding of PVA, forming new hydrogen bonds.

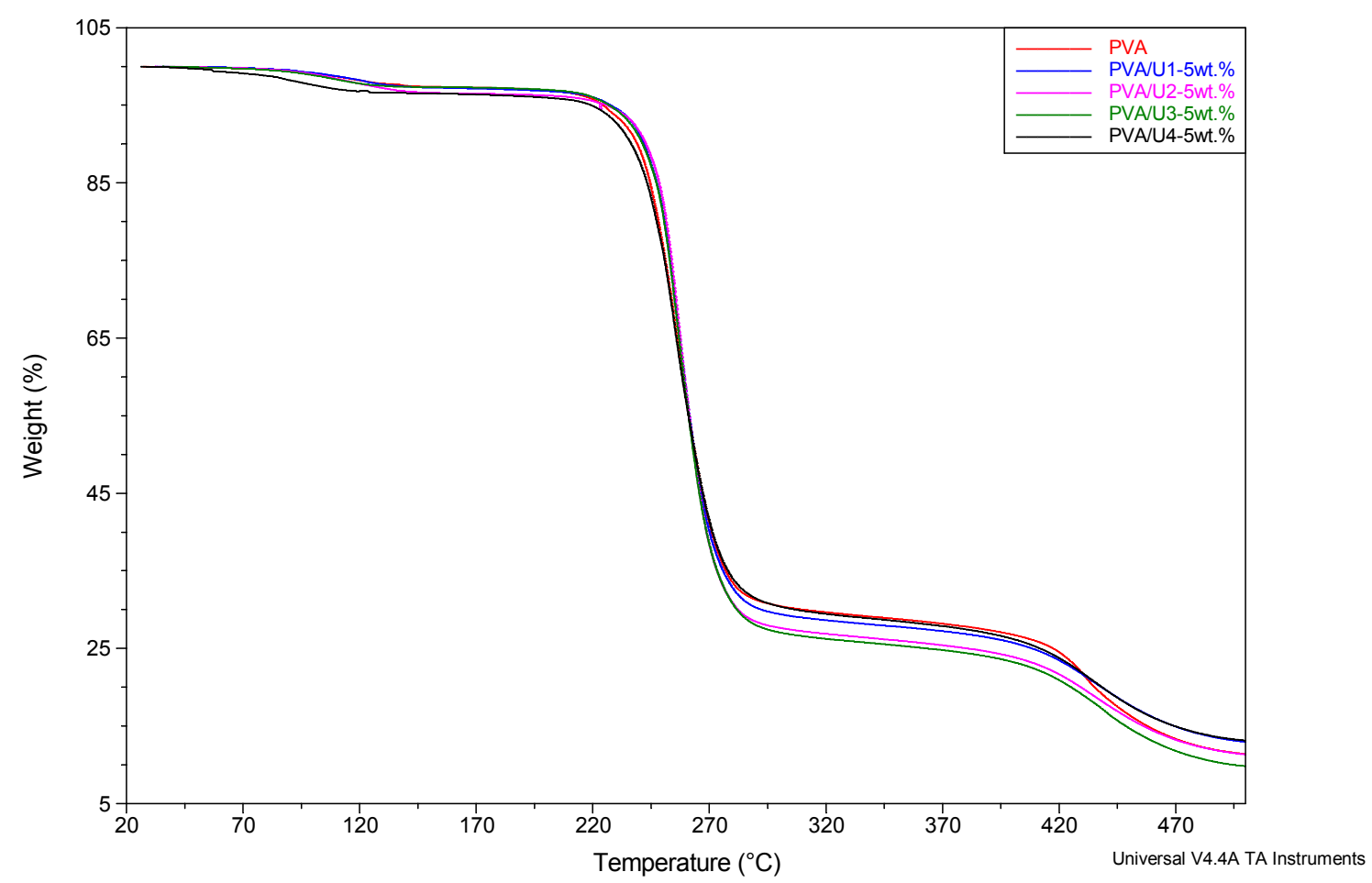

Fig.13. TGA diagrams of neat PVA and PVA composites containing $5 \%$ U1, U2, U3, and U4 fibers 
From TGA and DSC results, in terms of $T_{g}$ and $X_{c}$ values, it follows that most of the water present was bound water, with a limited lubrication effect. Correlating the values of composites crystallinity with the content of water (Tables 5 and 6), one can observe that PVA/U1 and PVA/U3 composites, with lower water content (2.5 to 2.6\%), showed the highest crystallinity degree (ca. 55\%, three percent higher than that of neat PVA), and the composites with higher water content (3.2 to $3.4 \%$ ) a crystallinity degree close to that of neat PVA. These results highlight the role of cellulose fibers in increasing the crystallinity of the matrix, probably by their nucleating effect, an effect that is diminished by the action of water, which disrupts the regular structure of PVA and decreases its crystallinity.

Figure 13 shows that a second degradation region was located between 210 and $300{ }^{\circ} \mathrm{C}$; this was attributed to the pyrolysis of cellulose fibers and to the degradation of PVA films, the weight loss being around $70 \%$ for all the samples. As reported by Qua et al. (2009), the second stage of degradation mainly involves dehydration reactions and the formation of volatile products. The third stage weight loss occurred above $400{ }^{\circ} \mathrm{C}$ and involves the decomposition of carbonaceous matter (Lee et al. 2009).

Table 6. TGA Data of Neat PVA and PVA Composites Containing 5 wt.\% Fibers

\begin{tabular}{||l|c|c|c||}
\hline Samples & $\begin{array}{c}\text { Water } \\
\text { content } \\
\%\end{array}$ & $\begin{array}{c}T_{\text {on }} \\
{ }^{\circ} \mathrm{C}\end{array}$ & $\begin{array}{c}T_{d} \\
{ }^{\circ} \mathrm{C}\end{array}$ \\
\hline PVA & 2.3 & 238.7 & 260.8 \\
\hline PVA/5\%U1 & 2.5 & 242.1 & 261.4 \\
\hline PVA/5\%U2 & 3.2 & 241.4 & 261.5 \\
\hline PVA/5\%U3 & 2.6 & 241.9 & 261.3 \\
\hline PVA/5\%U4 & 3.4 & 241.5 & 259.0 \\
\hline
\end{tabular}

It can be observed in Fig. 13 that the differences in TGA curves were negligible for neat PVA and PVA composites. Nevertheless, a slight increase of the onset degradation temperatures of the composites in comparison to neat PVA was observed. Also, the major degradation peak $T_{d}$ shifted, in general, to higher temperatures. This behavior highlights the effect of cellulose fibers in increasing the thermal stability of PVA. Lee et al. (2009) observed that a higher amount of cellulosic reinforcement led to higher thermal stability in PVA.

PVA composite with U4 cellulose fibers was different from the other composites, showing higher toughness and rigidity, based on the results of mechanical characterization, but showing the lowest crystallinity based on the results of thermal characterization. The smaller size of these fibers and the expected stronger matrix/fiber interaction can explain both the improvement of mechanical behavior and the decrease of crystallinity, because the new bonding between PVA and fibers can affect the crystalline structure of PVA. The weak influence of PVA crystallinity in enhancing mechanical properties was also obvious. 


\section{CONCLUSIONS}

1. Cellulose nanofibers were obtained from microcrystalline cellulose by applying different ultrasonication conditions. The values of ultrasonication parameters (power and time) influenced the size and the amount of cellulose nanofibers: higher power and, respectively, time of ultrasonication led to higher yields of nanofibers with smaller size.

2. FE-SEM images showed pieces of undefibrilated MCC and many fibers with a diameter of 70 to $150 \mathrm{~nm}$ in the case of fibers prepared with the lower ultrasonication power and the lower time of sonication (U1). Smaller diameters, from 10 to $100 \mathrm{~nm}$ were detected when a higher time of sonication was applied (U2), and nanofibers of cellulose with very small dimension $(<20 \mathrm{~nm})$ in case of higher ultrasonication power (U3 and U4).

3. AFM phase and amplitude images of cellulose nanofibers showed the presence of bundles of long cellulose fibers in the nanometer scale in case of U1 and U4 nanofibers. In case of U1 nanofibers larger diameters were obtained, along with nonfibrillar inclusions, like in the case of FE-SEM images. The diameter of U1 nanofibers, determined based on AFM height images, was in a range from $22.0 \mathrm{~nm}$ to $126.6 \mathrm{~nm}$, unlike the diameter of U4 nanofibers, which was in a range from $11.4 \mathrm{~nm}$ to $31.9 \mathrm{~nm}$. Both FE-SEM and AFM investigations confirmed that cellulose fibers with diameters in nanometric range were obtained.

4. No important differences in terms of crystallinity $(C I)$ between MCC and U1 to U4 samples were obtained after ultrasonication treatment. Both the inter-planar distances $d_{002}$ and the integrated half width $\beta_{002}$ remained unchanged, within the measurement errors, regardless the different ultrasonic parameters used.

5. The obtained cellulose fibers, used in small concentration as reinforcements in a PVA matrix, resulted in important increases of both tensile strength and modulus, especially at lower loadings. The enhancement of mechanical properties of PVA composites in comparison to neat PVA was explained by the good adhesion at the fiber/matrix interface through hydrogen bonding between the $\mathrm{OH}$ groups of cellulose fibers and similar groups of the PVA matrix. Better mechanical properties were obtained in the case of PVA composites containing smaller size fibers (U3 and U4) in comparison to those containing larger size fibers (U1 or U2). The higher interfacial area and the larger probability of hydrogen bonding in the case of smaller size fibers was supposed to explain the higher reinforcing effect observed.

6. No significant changes for $T_{g}$ and $T_{m}$ of PVA composites with reference to neat PVA were observed in DSC diagrams, but a slight increase in crystallinity was observed. The stronger interactions between cellulose fiber surface and adjacent PVA chains in case of smaller size fibers and the influence of water were proposed to explain these results.

7. Slightly higher onset degradation temperatures were obtained for PVA composites in comparison to neat PVA, showing an increase of the thermal stability caused by the addition of cellulose fibers. 


\section{ACKNOWLEDGEMENT}

Funding for this research was provided by National Center of Management of Programs - Partnership, grant no. 32-172.

\section{REFERENCES CITED}

Alemdar, A., and Sain, M. (2008). "Biocomposites from wheat straw nanofibers: Morphology, thermal and mechanical properties," Composites Science and Technology 68(2), 557-565.

Azizi, S., Sanchez, J., and Dufresne, A. (2005). "Nanocomposite polymer electrolyte based on polyoxiethylene and cellulose whiskers," Polymeros: Ciencia e Tecnologia 15(2), 109-113.

Bondeson, D., Mathew, A., and Oksman, K. (2006). "Optimization of the isolation of nanocrystals from microcrystalline cellulose by acid hydrolysis," Cellulose 13(2), 171-180.

Chakraborty, A., Sain, M., and Kortschot M. (2005). "Cellulose microfibrils: A novel method of preparation using high shear refining and cryocrushing," Holzforschung 59, 102-107.

Chen, W., Yu, H., Liu, Y., Chen, P., Zhang, M., and Hai Y. (2010). “Individualization of cellulose nanofibers from wood using high-intensity ultrasonication combined with chemical pretreatments," Carbohydrate Polymers, in press, available online 27 October 2010

Cheng, Q., and Wang, S. (2008). "A method for testing the elastic modulus of single cellulose fibrils via atomic force microscopy," Composites Part A: Appl. Sci. Manufg. 39(12), 1838-1843.

Cheng, Q., Wang, S., and Han, Q. (2010). "Novel process for isolating fibrils from cellulose fibers by high-intensity ultrasonication. II. Fibril characterization," J. Appl. Polym. Sci. 115(5), 2756-2762.

Coleman, J. N., Cadek, M., Blake, R., Nicolosi, V., Ryan, K. P., Belton, C., Fonseca, A., Nagy, J. B., Gun'ko, Y. K., and Blau, W. J. (2004). "High performance nanotubereinforced plastics: Understanding the mechanism of strength increase," Adv. Funct. Mater. 14(8), 791-798.

De Souza Lima, M., and Borsali, R. (2004). "Rodlike cellulose microcrystals: Structure, properties, and applications," Macromolecular Rapid Communications 25(7), 771787.

Dong, S. P., and Roman, M. (2007). "Fluorescently labeled cellulose nanocrystals for bioimaging applications," J. Amer. Chem. Soc. 129(45), 2007, 13810-13811.

Eichhorn, S. J., Dufresne, A., Aranguren, M., Marcovich, N. E., Capadona, J. R., Rowan, S. J., Weder, C., Thielemans, W., Roman, M., Renneckar, S., Gindl, W., Veigel, S., Keckes, J., Yano, H., Abe, K., Nogi, M., Nakagaito, A. N., Mangalam, A., Simonsen, J., Benight, A. S., Bismarck, A., Berglund L. A., and Peijs, T. (2010). "Review: Current international research into cellulose nanofibres and nanocomposites," Journal of Materials Science 45(1), 1-33. 
Elazzouzi-Hafraoui, S., Nishiyama, Y., Putaux, J. L., Heux, L., Dubreuil, F., and Rochas, C. (2008). "The shape and size distribution of crystalline nanoparticles prepared by acid hydrolysis of native cellulose," Biomacromol. 9(1), 57-65.

Famá, L., Gerschenson, L., and Goyanes, S. (2009). "Starch-vegetable fibre composites to protect food products," Carbohydrate Polymers 75(2), 230-235.

Filson, P. B., and Dawson-Andoh B. E. (2009). "Sono-chemical preparation of cellulose nanocrystals from lignocellulose derived materials," Bioresource Technology 100(7), 2259-2264.

Hoenich, N. (2006). "Cellulose for medical applications: Past, present, and future," BioResources 1(2), 270-280.

$\mathrm{Hu}, \mathrm{H}$., and Chen, G., (2010). "Electrochemically modified graphite nanosheets and their nanocomposite films with poly(vinyl alcohol)," Polymer Composites 31(10), 17701775.

Hubbe, M. A., Rojas, O. J., Lucia, L. A., and Sain, M. (2008). “Cellulosic nanocomposites: A review," BioResources 3(3), 929-980.

Hui, S., Chaki, T. K., and Chattopadhyay, S. (2008). "Effect of silica-based nanofillers on the properties of a low-density polyethylene/ethylene vinyl acetate copolymer based thermoplastic elastomer", J. Appl. Polym. Sci. 110(2), 825-836.

Ioelovich, M. (2008) "Cellulose as a nanostructured polymer: A short review," BioResources 3(4), 1403-1418.

Jonoobi, M., Harun, J., Shakeri, A., Misra, M., and Oksman, K. (2009). "Chemical composition, crystallinity, and thermal degradation of bleached and unbleached kenaf bast (Hibiscus cannabinus) pulp and nanofibers," BioResources 4(2), 626-639.

Kamel, S. (2009). "Nanotechnology and its applications in lignocellulosic composites, A mini review," eXPRESS Polymer Letters 1(9), 546-575.

Kvien, I., and Oksman, K. (2007). "Orientation of cellulose nanowhiskers in polyvinyl alcohol (PVA)," Applied Physics A: Materials Science and Processing 87(4), 641643.

Kvien, I., Sugiyama, J., and Oksman, K. (2007). "Characterization of starch based nanocomposites," J. Mat. Sci. 42(19), 8163-8171.

Lee, S. Y., Mohan, D. J., Kang, I. A., Doh, G. H., Lee, S., and Han, S. O. (2009). "Nanocellulose reinforced PVA composite films: Effects of acid treatment and filler loading," Fibers and Polymers 10(1), 77-82.

Lee, K. B. (2006). "Two-step activation of paper batteries for high power generation: Design and fabrication of bioflued- and water-activated paper batteries," $J$. Micromechanics and Microengineering 16(11), 2312-2317.

Li, Q., and Renneckar, S. (2009). "Molecularly thin nanoparticles from cellulose: Isolation of sub-microfibrillar structures," Cellulose 16(6), 1025-1032.

Lu, J., Wang, T., and Drzal, L. T. (2008). "Preparation and properties of microfibrillated cellulose polyvinyl alcohol composite materials," Composites: Part A 39(5), 738-746.

Mathew A. P., and Dufresne A. (2002). "Morphological investigation of nanocomposites from sorbitol plasticized starch and tunicin whiskers," Biomacromolecules 3(3), 60917. 
Nakagaito, A. N., and Yano, H. (2004). "The effect of morphological changes from pulp fiber towards nano-scale fibrillated cellulose on the mechanical properties of highstrength plant fiber based composites," Appl. Phys. A 78(4), 547-552.

Nakagaito, A. N., and Yano, H. (2008). "The effect of fiber content on the mechanical and thermal expansion properties of biocomposites based on microfibrillated cellulose," Cellulose 15(4), 555-559.

Nogi, M., Shinsuke, I., Kentaro, A., Keishin, H., Nakagaito, A. N., and Hiroyuki, Y. (2006). "Fiber-content dependency of the optical transparency and thermal expansion of bacterial nanofiber reinforced composites," Appl. Phys. Lett. 88(13), 133124133127.

Oksman, K., Mathew, A. P., Bondeson, D., and Kvien I. (2006). "Manufacturing process of cellulose whiskers/polylactic acid nanocomposites," Composites Science and Technology 66(15), 2776-2784.

Panaitescu, D. M., Donescu, D., Bercu, C., Vuluga, D. M., Iorga, M. D., and Ghiurea, M. (2007a) "Polymer composites with cellulose microfibrils," Polym. Eng. Sci. 47(8), 2007, 1128-1234.

Panaitescu, D. M., Nechita, P., Iovu, H., Iorga, M. D., Ghiurea, M., and Serban, D. (2007b). "Compozite din polipropilena si microfibrile celulozice obtinute prin tratamente mecano - chimice," Materiale Plastice 44(3), 195-198.

Panaitescu, D. M., Nothingher, P. V., Ghiurea, M., Ciuprina, F., Paven, H., Iorga, M. D., and Florea, D. (2007c). "Properties of composite materials from polyethylene and cellulose microfibrils," J. of Optoelectronics and Advanced Materials 9(8), 25242528.

Park, S., Baker, J. O., Himmel, M. E., Parilla, P. A. and Johnson, D. K. (2010). "Cellulose crystallinity index: Measurement techniques and their impact on interpreting cellulase performance," Biotechnology for Biofuels 3(5), 1-10.

Peresin, M. S., Habibi, Y., Vesterinen, A.-H., Rojas, O. J., Pawlak, J. J., and Sepp, J. V. (2010). "Effect of moisture on electrospun nanofiber composites of poly(vinyl alcohol) and cellulose nanocrystals," Biomacromolecules 11(9), 2471-2477.

Petersson, L., and Oksman, K. (2006). "Biopolymer based nanocomposites: Comparing layered silicates and microcrystalline cellulose as nanoreinforcement," Composites Science and Technology 66(13), 2187-2196.

Petersson, L., Kvien, I., Oksman, K. (2007) "Structure and thermal properties of poly(lactic acid)/cellulose whiskers nanocomposite materials," Composite Science and Technology 67(11-12), 2535-2544

Petersson, L., Mathew, A. P., and Oksman, K. (2009) 'Dispersion and properties of cellulose nanowhiskers and layered silicates in cellulose acetate butyrate nanocomposites," J. Appl. Polym. Sci. 112(4), 2001-2009.

Qua, E. H., Hornsby, P. R., Sharma, H. S. S., Lyons, G., and McCall, R. D. (2009). "Preparation and characterization of poly(vinyl alcohol) nanocomposites made from cellulose nanofibers," J. Appl. Polym. Sci. 113(4), 2238-2247.

Roohani, M., Habibi, Y., Belgacem, N. M., Ebrahim, G., Karimi, A. N., and Dufresne, A. (2008). "Cellulose whiskers reinforced polyvinyl alcohol copolymers nanocomposites," European Polymer J. 44(8), 2489-2498. 
Sedlarık, V., Saha, N., Kuritka, I., and Saha, P. (2006). “Characterization of polymeric biocomposite based on poly(vinyl alcohol) and poly(vinyl pyrrolidone)," Polym. Compos. 27(2), 147-152.

Tang, Y., Du, Y., Li, Y., Wang, X., and Hu, X. (2009). “A thermosensitive chitosan/poly(vinyl alcohol) hydrogel containing hydroxyapatite for protein delivery," J. Biomed. Mater. Res. 91(4), 953-963.

Wang, S., and Cheng, Q. (2009). "A novel process to isolate fibrils from cellulose fibers by high-intensity ultrasonication, Part 1: Process optimization," J. Appl Polym Sci. 113(2), 1270-1275.

Wang, B., and Sain, M. (2007). "The effect of chemically coated nanofiber reinforcement on biopolymer based nanocomposites," BioResources 2(3), 371-388.

Wu, Y., Zhou D. G., Wang, S. Q., and Zhang, Y. (2009). "Polypropylene composites reinforced with rice straw micro/nano fibrils isolated by high intensity ultrasonication," BioResources 4(4), 1487-1497.

Yano, H., Sugiyama, J., Nakagaito, A. N., Nogi, M., Matsuura, T., Hikita, M., and Handa, K. (2005). "Optically transparent composites reinforced with networks of bacterial nanofibers," Advanced Materials 17(2), 153-155.

Yano, H., and Nakahara, S. (2004). "Bio-composites produced from plant microfiber bundles with a nanometer unit web-like network," J. Mater. Sci. 39(5), 1635-1638.

Yan, L., and Gao, Z. (2008). "Dissolving of cellulose in PEG/NaOH aqueous solution," Cellulose 15(6), 89-796.

Yuan, X. P., and Ding, E. Y., (2006). "Synthesis and characterization of storage energy materials prepared from nano-crystalline cellulose/polyethylene glycol," Chinese Chem. Lett. 17(8), 1129-1132.

Zhang, Y. P., Lee, S. H., Reddy, K. R., Gopalan, A. I., and Lee, K. P. (2007). "Synthesis and characterization of core-shell $\mathrm{SiO}_{2}$ nanoparticles/poly(3-aminophenylboronic acid) composites," J. Appl. Polym. Sci. 104(4), 2743-2750.

Zhang, H., Wang Q., and Li L. (2009). "Dehydration of water-plasticized poly(vinyl alcohol) systems: Particular behavior of isothermal mass transfer," Polym. Int. 58, 97104.

Zhang, J., Elder, T. J., Pu, Y., and Ragauskas, A. J. (2007). "Facile synthesis of spherical cellulose nanoparticles," Carbohydrate Polymers 69(3), 607-611.

Article submitted: September 20, 2010; Peer review completed: October 15, 2010; Revised version received: December 16, 2010; Accepted: December 22, 2010; Published: December 28, 2010; with minor text corrections January 13, 2011. 